\title{
Active Razor Shell CaO Catalyst Synthesis for Jatropha Methyl Ester Production via Optimized Two-Step Transesterification
}

\author{
A. N. R. Reddy, ${ }^{1}$ A. A. Saleh, ${ }^{1}$ M. S. Islam, ${ }^{2}$ and S. Hamdan ${ }^{1}$ \\ ${ }^{1}$ Department of Mechanical and Manufacturing Engineering, Faculty of Engineering, Universiti Malaysia Sarawak, \\ 94300 Kota Samarahan, Sarawak, Malaysia \\ ${ }^{2}$ Department of Chemistry, Bangladesh Army University of Engineering \& Technology, Qadirabad Cantonment, \\ Natore 6431, Bangladesh \\ Correspondence should be addressed to A. N. R. Reddy; amarnadha@gmail.com
}

Received 26 December 2016; Revised 23 February 2017; Accepted 7 March 2017; Published 12 April 2017

Academic Editor: Arghya Narayan Banerjee

Copyright @ 2017 A. N. R. Reddy et al. This is an open access article distributed under the Creative Commons Attribution License, which permits unrestricted use, distribution, and reproduction in any medium, provided the original work is properly cited.

Calcium based catalysts have been studied as promising heterogeneous catalysts for production of methyl esters via transesterification; however a few were explored on catalyst synthesis with high surface area, less particle size, and Ca leaching analysis. In this work, an active Razor shell $\mathrm{CaO}$ with crystalline size of $87.2 \mathrm{~nm}, S_{\mathrm{BET}}$ of $92.63 \mathrm{~m}^{2} / \mathrm{g}$, pore diameters of $37.311 \mathrm{~nm}$, and pore volume of $0.613 \mathrm{cc} / \mathrm{g}$ was synthesized by a green technique "calcination-hydro aeration-dehydration." Spectrographic techniques TGA/DTA, FTIR, SEM, XRD, BET\&BJH, and PSA were employed for characterization and surface morphology of CaO. Two-step transesterification of Jatropha curcas oil was performed to evaluate $\mathrm{CaO}$ catalytic activity. A five-factor-five-level, two-block, half factorial, central composite design based response surface method was employed for experimental analysis and optimization of Jatropha methyl ester (JME) yield. The regression model adequacy ascertained thru coefficient of determination $\left(R^{2}: 95.81 \%\right)$. A JME yield of $98.80 \%$ was noted at $C$ (3.10 wt.\%), $M(54.24 \mathrm{~mol} . / \mathrm{mol} . \%), T(127.87 \mathrm{~min}), H\left(51.31^{\circ} \mathrm{C}\right)$, and $R(612 \mathrm{rpm})$. The amount of Ca leached to JME during 1st and 4th reuse cycles was $1.43 \mathrm{ppm} \pm 0.11$ and $4.25 \mathrm{ppm} \pm 0.21$, respectively. Higher leaching of Ca, $6.67 \mathrm{ppm} \pm 1.09$, was found from the 5th reuse cycle due to higher dispersion of $\mathrm{Ca}^{2+}$; consequently JME yield reduces to $76.40 \%$. The JME fuel properties were studied according to biodiesel standards EN 14214 and comply to use as green biodiesel.

\section{Introduction}

The sustainability "strengthening the mechanisms for redistribution from the present to the future" has become a motto of all nations around the world, for promoting intrinsic scientific research methodologies into agriculture, materials, energy, economy, and even urban planning [1]. Despite multiphase research in energy, rising global warming and air pollution issues instigated by fossil fuel combustion besides limited petroleum fuel reserves have led to research for sustainable renewable energy sources. Fatty acid methyl ester (FAME), commercially known as biodiesels, introduced in the 1980s as a sustainable fuel energy resource for reducing greenhouse emissions [2]. FAME comprises monoalkyl ester of long fatty acids, typically produced by the transesterification of biologically produced feedstocks such as vegetable oil ( $\mathrm{VO})$, animal fats, and microalgae oils in the presence of methyl alcohol $(\mathrm{MeOH})$ and a suitable catalyst $[3,4]$. Transesterification reaction is a combination of three sequential catalyzed reactions (1)-(3) in which triglycerides (TG) of a VO were transformed to diglycerides (DG) and monoglyceride (MG) and finally as glycerol and methyl ester (ME) known as biodiesel [5]. Jatropha curcas Linnaeus, an euphorbia family member, has attained the researcher's attention as one of the best suited nonedible VO feedstock types due to its agromedical tangible interests as well as pro human food cycle nature, for biodiesel fuel (BF) production via transesterification [4]. Acid or base catalyzed transesterification of VO was largely reported in literature and also concluded on the use of heterogeneous catalysts for sustainable BF production [6,7].

$$
\begin{gathered}
\mathrm{TG}+\mathrm{MeOH} \stackrel{\text { Catalyst }}{\longleftrightarrow} \mathrm{DG}+\mathrm{ME} \\
\mathrm{DG}+\mathrm{MeoH} \stackrel{\text { Catalyst }}{\longleftrightarrow} \mathrm{MG}+\mathrm{ME}
\end{gathered}
$$




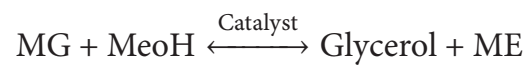

Catalytic activity of a solid catalyst is highly influenced by its surface area and particle size distribution $[8,9]$. Moreover, rate of a reaction among the reactants significantly accelerates with lower particle catalysts since it improves the diffusion forces over catalyst particle surfaces and better mass flow channels $[8,10]$. In addition, this phenomenon ensures higher reaction rate through availability of large number of active reactant molecules that need a minimal activation energy. Calcium based catalysts demonstrate key promising characteristics that include higher basicity, lesser solubility, better reusability, low costs, and easy availability. A large number of studies have been devoted to investigate biodiesel applications of pure or mixed calcium catalysts [11-15]. Buasri et al. [10] produced biodiesel from palm oil using $\mathrm{CaO}$ catalyst which synthesized various seashells that include mussel, cockle, and scallop and reported surface areas $\left(S_{\mathrm{BET}}\right)$ of $89.91 \mathrm{~m}^{2} / \mathrm{g}, 59.87 \mathrm{~m}^{2} / \mathrm{g}$, and $74.96 \mathrm{~m}^{2} / \mathrm{g}$, respectively. Shan et al. [16] studied Ca-based heterogeneous catalyst perspectives synthesized using rich waste materials such as bones, mollusk shells, egg shells, and industrial wastes besides catalytic activity and biodiesel applications of calcium catalysts prospects and challenges were discussed. Mohamed et al. [17] derived $\mathrm{CaO}$ from cockle shell by calcination at $850^{\circ} \mathrm{C}$, while Nurdin [18] derived $\mathrm{CaO}$ catalyst from Paphia undulata shell wastes through calcination at $680^{\circ} \mathrm{C}$ for transesterification of Jatropha curcas oil (JCO) and Rubber oil to biodiesel. Choudhury et al. [11], Teo et al. [12], and TaufiqYap et al. [13] investigated the transesterification of JCO using $\mathrm{CaO}$ of $S_{\text {BET }} 7.114 \mathrm{~m}^{2} / \mathrm{g} ; 9.2 \pm 0.80 \mathrm{~m}^{2} / \mathrm{g}$; and $9.5 \mathrm{~m}^{2} / \mathrm{g}$ and obtained a biodiesel of $89.36 \%, 90 \%$, and $85 \%$, respectively, while Margaretha et al. [19] experimented with Pomacea sp. shells produced $\mathrm{CaO}$ with pore volume of $0.04 \mathrm{cc} / \mathrm{g}$ and $S_{\mathrm{BET}}$ of $17 \mathrm{~m}^{2} / \mathrm{g}$ for transesterification palm oil to biodiesel. Tan et al. [14] investigated the transesterification kinetics of waste cooking oil to biodiesel using $\mathrm{CaO}$ catalyst synthesized from ostrich and chicken-eggshells besides their $S_{\mathrm{BET}}$ of $71.0 \mathrm{~m}^{2} / \mathrm{g}$ and $54.6 \mathrm{~m}^{2} / \mathrm{g}$, respectively. Islam et al. [20] synthesized nano- $\mathrm{CaCO}_{3}$ with particle of $20 \pm 5 \mathrm{~nm}$ diameter from cockle shells by grinding mechanically in the presence of dodecyl dimethyl betaine. De Sousa et al. [21] investigated transesterification kinetics of soybean oil using commercial $\mathrm{CaO}$, egg shell $\mathrm{CaO}$, carb shell CaO $S_{\mathrm{BE}}$ of $0.9 \mathrm{~m}^{2} / \mathrm{g}, 4.3 \mathrm{~m}^{2} / \mathrm{g}$, and $4.0 \mathrm{~m}^{2} / \mathrm{g}$, and particle size of $56 \mathrm{~nm}, 184 \mathrm{~nm}$, and $74 \mathrm{~nm}$, respectively.

The significant transesterification reaction parameters that influence JME yield include catalyst loading, methanol to oil ratio, reaction time, heating temperature, and the stirring rpm [22-26]. Many researchers explored optimal parametric sufficiency over their minimum and maximum levels. The intrinsic impact of a parameter and their potential interactions to achieve the optimal FAME yield was investigated using the response surface methodology (RSM) as an optimization and statistical analysis tool [11, 22, 27]. RSM was widely adopted based on three designs of CCD; CCRD [22, 27]; and Box-Behnken design [11] for optimal FAME. Vicente et al. [28] testified over two factors, temperature $\left(20^{\circ} \mathrm{C}-75^{\circ} \mathrm{C}\right)$ and catalyst concentration (0.2-1.8 wt.\%), using sunflower oil in the presence of various homogeneous and heterogeneous catalysts. Goyal et al. [23] reported the impact of four reaction parameters including the methanol-oil ratio, reaction time, $\mathrm{NaOH}$ catalyst concentration, and temperature over transesterification of JCO. A CCD based four-factorfive-level was utilized to analyze the parametric impact on the FAME yield. An optimal FAME field of $98.3 \%$ was reported at $11: 1$ molar ratio, $1 \mathrm{wt} . \%$ catalyst, $54^{\circ} \mathrm{C}$ temperature, and $110 \mathrm{~min}$ of reaction time, while Dhingra et al. investigated Karanja [29] and Jatropha [30] biodiesels production optimization by considering five reaction parameters using the RSM coupled with GA [29]. Many studies reported that the choice of reaction parameters directly contributes in biodiesel conversion process and influences FAME yield. Also, it is noted that reaction parameters, both stirring speed and reaction time, were less studied.

The literature studies emphasize suitability of calcium catalyst for biodiesel production via transesterification. Besides, higher surface area, large pores, and lesser particle size of a catalyst enhance their catalytic efficacy of transesterification reaction [11-15]. Ensis arcuatus has been commonly found to be fishery food source in the sandy coastal locations of Pacific and Antarctic areas and regionally referred to as Razor clams. The study reports of Kanakaraju et al. [31], Akmar and Rahim [32], and Hossen et al. [33] demonstrate potential of Razor clams marine life and abundance in the state of Sarawak as well as in the west Malaysian provinces. The previous works on synthesis of calcium catalysts are very limited and have been focused on increasing catalyst surface area and lowering the particle size from naturally available renewable wastes such as aquatic seashells [18, 20, 21, 34-38]. However, according to the best of our broad literature survey, no work has reported on activated $\mathrm{CaO}$ nanocatalyst synthesis using Razor shells. Moreover, a very scant work was accounted on the study on kinetics of transesterification reaction parameters that include catalyst loading, methanol to oil ratio, heating temperature, stirring speed, and reaction time, which need to be undertaken.

In this study, $\mathrm{CaO}$ of high surface area and pores as well as lower particle size was synthesized from a seashell so as to result in an activated heterogeneous catalyst. Besides, the direct and interaction impacts of five reaction parameters on the FAME yield were proposed to be investigated over JCO two-step transesterification process. Activated $\mathrm{CaO}$ was synthesized using locally available seashell species, Razor shells. A laboratory scale experimental protocol "calcinationhydro aeration-dehydration" was developed for Razor shell $\mathrm{CaO}$ synthesis; besides, structural and morphological characteristics were analyzed. The transesterification reaction kinetics was studied by employing a CCD based on the fivefactor-five-level, two-block, half factorial, RSM model. JME production optimization protocol using active Razor shell $\mathrm{CaO}$ catalyst is shown in "Scheme 1." The catalyst stability, reusability, and leaching were investigated. The synthesized JME fuel properties were tested according to the biodiesel standards EN14214. 


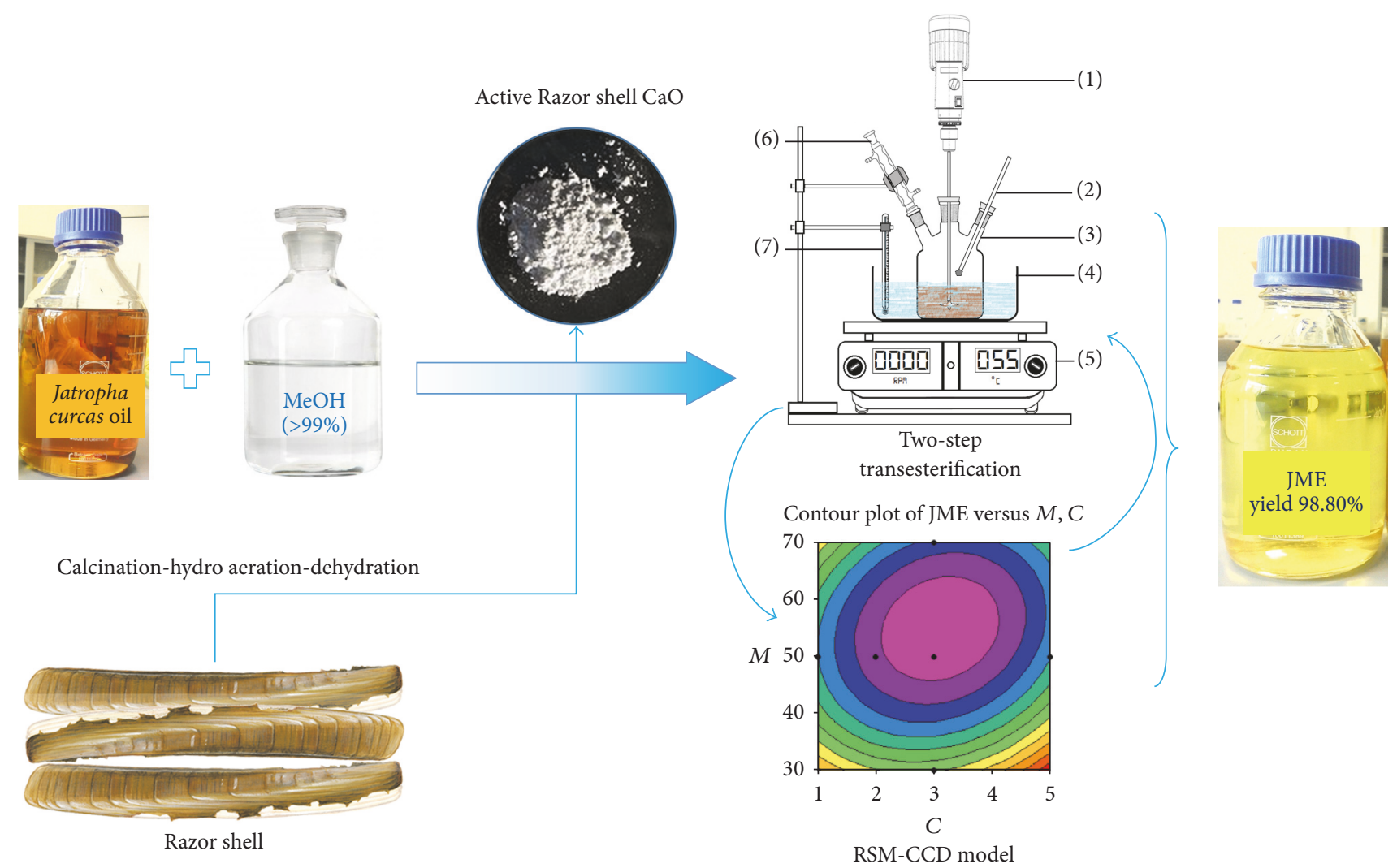

SCHeme 1: Jatropha methyl ester production optimization using active Razor shell $\mathrm{CaO}$ catalyst.

\section{Material and Method}

The Jatropha curcas seeds were obtained from a Jatropha farm, Wahaba Sdn. Bhd., situated in Sarawak, Malaysia. Jatropha curcas oil (JCO) was extracted mechanically using an oil expelling machine from their dried seeds. The crude JCO was used as extracted without any processing like purification or refining. JCO fatty acid profile was determined by the gas chromatography and the results are as indicated in Table 6. The acid value (A) and saponification value (S) of JCO were measured as $29.46 \mathrm{mg} \mathrm{KOH} / \mathrm{g}$ and $210.04 \mathrm{mg} \mathrm{KOH} / \mathrm{g}$, respectively, by utilizing a standard procedure [39]. The molecular weight $(M)$ of JCO was resulted as $932 \mathrm{~g} / \mathrm{mol}$. by the equation $M=(56.1 \times 1000 \times 3) /(\mathrm{SV}-\mathrm{AV})$ [39]. Laboratory grade chemicals that include sulfuric acid (99.9\%), methyl alcohol (>99\%), potassium hydroxide (95\%), calcium oxide (CAS.NO.0001305788), and double distilled deionized water were utilized. All experiments were conducted at the Energy Laboratory, Department of Mechanical and Manufacturing Engineering, Faculty of Engineering, Universiti Malaysia Sarawak (UNIMAS), Malaysia.

2.1. Preparation of Active Razor Shells CaO Catalyst. Razor shells were collected from a local community market at Muara Tebas, Sawarak, Malaysia. The $\mathrm{CaO}$ catalyst was synthesized following "calcination-hydro aeration-dehydration" of the Razor shell. The synthesis protocol is adopted as described before by Niju et al. [40, 41] and modified to get a fine Razor shell powder. In a nutshell, about 500 gm of Razor shells was thoroughly water washed and dried overnight at $105^{\circ} \mathrm{C}$ in a hot air oven (IMPACT, Scotland, UK) [42]. The dried Razor shell was finely crushed using a heavy duty professional blender (OmniBlend V, imbaco, Australia) and then sieved using an $80 \mu \mathrm{m}$ mesh. The micron-sized Razor shells powder was calcinated in a high temperature muffle furnace (KSL-1700X-A4, MTI Corporation, USA), at a target temperature of $850^{\circ} \mathrm{C}$ for $2.5 \mathrm{~h}$. At a calcine temperature of $850^{\circ} \mathrm{C}, \mathrm{CaCO}_{3}$ of Razor shell decomposes as $\mathrm{CaO}$ and $\mathrm{CO}_{2}$. The fine $\mathrm{CaO}$ powder was refluxed in water for $6 \mathrm{~h}$ at $60^{\circ} \mathrm{C}$. Simultaneously, the mixture was aerated using spherical and cylindrical air stone bubbler setup fitted with a Hi-blow air pump (HAP-60, 0.01 Mpa, $60 \mathrm{w}$ Hailea) and then the mixture was allowed to settle for $2 \mathrm{~h}$. Continuous aeration oxygenates refluxing mixture and precipitates heavy dirt and solid particles which results in refined highly pores Razor shell $\mathrm{CaO}$ particles. The catalyst was filtered and dried overnight at $120^{\circ} \mathrm{C}$ in an oven [42]. The refined Razor shell solid powder was grounded for high grade fine catalyst particles utilizing a Planetary Ball mill (PM 400, Retsch, Germany) at $250 \mathrm{rpm}$ for $2 \mathrm{~h}$. Calcination of fine Razor shell $\mathrm{CaO}$ was carried out for $3 \mathrm{~h}$ at $600^{\circ} \mathrm{C}$ so as to transform hydroxides to oxide form through dehydration. Accordingly, an active Razor shell $\mathrm{CaO}$ catalyst was synthesized following "calcination-hydro aeration-dehydration" protocol.

2.2. Characterization of Razor Shells CaO Catalyst. To investigate the organic structural features of Razor shell CaO catalyst, newly synthesized $\mathrm{CaO}$ and lab grade $\mathrm{CaO}$ samples were 
characterized using infrared spectrometer (Perkin Elmer, 100 series) over wavelengths 4000 to $280 \mathrm{~cm}^{-1}$. Thermogravimetric analyzer equipped with high temperature furnace (Mettler-Toledo, Switzerland) was employed for thermogravimetric and differential thermal analysis (TG/DTA) of Razor shell catalyst. Thermal analysis of samples was performed $35^{\circ} \mathrm{C}-1000^{\circ} \mathrm{C}$ at a heating rate of $10^{\circ} \mathrm{C} / \mathrm{min}$ and airflow of $100 \mathrm{ml} / \mathrm{min}$. Razor shell $\mathrm{CaO}$ catalyst and lab grade $\mathrm{CaO}$ crystalline features were studied employing $\mathrm{X}$-ray diffraction (XRD) method (Shimadzu 6000 ) over $20-80^{\circ} \mathrm{C}$ at a scanning angle of $2 \theta$ and frequency of $2^{\circ} \mathrm{C}$ per minute. Scherrer's equation, $D=0.9 \lambda / \beta \cos \theta$, was applied to calculate $\mathrm{CaO}$ particle average crystalline size, where " $D$ " denotes average crystalline size of $\mathrm{CaO}$ in $\mathrm{nm}, \lambda$ equals $1.542 \AA$, X-ray radiation wavelength, " $\beta$ " denotes full width at half maximum intensity in radians, and " $\theta$ " denotes Bragg angle in degrees. Razor shell $\mathrm{CaO}$ catalyst surface morphology was analyzed with scanning electron microscopy (SEM TM3030, Hitachi, Japan). The newly synthesized Razor shell $\mathrm{CaO}$ catalyst surface area, pore diameter and pore volume, calcined nonaerated $\mathrm{CaO}$, unclacined Razor shell, and reference- $\mathrm{CaO}$ powder samples were investigated utilizing the BET (BrunauerEmmett-Teller) and BJH (Barrett-Joyner-Halenda) protocols (Autosorb iQ-AG-C, Quantachrome instruments, USA). Both aerated and nonaerated $\mathrm{CaO}$ samples of Razor shell's particle size distribution were studied using particle size distribution analyzer (PSA 1090, $0.04 \mu \mathrm{m}-500 \mu \mathrm{m}$, CILAS, France). The basic strength (H_) of Razor shell catalyst was determined by employing Hammett indicators. Typically, a solution mixture of $1 \mathrm{ml}$ of Hammett indicator and $20 \mathrm{ml}$ of methanol was prepared and added to $25 \mathrm{mg}$ of catalyst sample. The contents were shaken well to attain homogeneity and left for $2 \mathrm{~h}$ to equilibrate and then catalyst color change was noted [43]. The following Hammett indicators were utilized: phenolphthalein $\left(\mathrm{H}_{-}=8.2\right)$, thymolphthalein $\left(\mathrm{H}_{-}=\right.$ 10.0), 2,4-dinitroaniline $\left(\mathrm{H}_{-}=15.0\right)$, and 4-nitroaniline $\left(\mathrm{H}_{-}=\right.$ 18.4). By adding a Hammett indicator to the catalyst sample, if it displays a change in color which infers that basicity of the catalyst is stronger compared to the Hammett indicator used, on the contrary the catalyst sample is to be labeled as a weaker than the probe Hammett indicator [44].

2.3. Jatropha Methyl Ester Production. Jatropha methyl ester (JME) production was carried out by following an in-house laboratory protocol. The high free fatty acids (FFA) and moisture contents of JCO strongly influence JME production through the catalyzed transesterification reaction [45]. JCO of FFA value $>3 \%$ and moisture content $>1$ wt. $\%$ which lead to saponification and oil hydrolysis besides reducing rate of biodiesel yield [46]. Hence, a two-step transesterification process was adopted [47]. The first step is acid esterification in which FFA of JCO reduced to a suitable minimum level followed by the second step which is base catalyzed transesterification [48]. The successive steps which involved acid esterification and catalyzed transesterification are explained in the following sections.

2.4. Acid Esterification. A digital hot plate magnetic stirrer mixer (MS300-BANTE make $300^{\circ} \mathrm{C}, 2 \mathrm{~L}, 220 \mathrm{~V}, 1250 \mathrm{rpm}$ ) and a $500 \mathrm{ml}$ two-neck flat bottom glass reactor are attached to a water cooled reflex condenser used for the acid esterification of JCO. In order to improve the JCO conversion process and enhance the JME yield, esterification was carried out using methanol and concentrated $\mathrm{H}_{2} \mathrm{SO}_{4}$ as a catalyst as mentioned in (4). An amount of $100 \mathrm{ml} \mathrm{JCO}$ was preheated at $110^{\circ} \mathrm{C}$ for $30 \mathrm{~min}$ to get moisture-free oil. A mixture of $60 \%$ $(\mathrm{v} / \mathrm{v})$ methanol and $1 \%(\mathrm{v} / \mathrm{v})$ catalyst to JCO was prepared and added to the JCO. The mixture was vigorously stirred at $200 \mathrm{rpm}$ and then heated to $50^{\circ} \mathrm{C}$ for $1 \mathrm{~h}$. After the reaction, the reactant mixture was allowed to settle for $1 \mathrm{~h}$ and then washed successively thrice using double distilled deionized water. Finally, the oil portion was duly dried at $110^{\circ} \mathrm{C}$ to prepare moisture-free oil. As a result of acid esterification, FFA of JCO was noted all in a minimum of $1 \%$ with an esterification rate of $98.4 \%$. Thus, the esterified JCO was suitable for the transesterification with base catalyst [48].

$$
\mathrm{RCOOH}+\mathrm{CH}_{3} \mathrm{OH} \stackrel{\mathrm{H}_{2} \mathrm{SO}_{4}}{\Longrightarrow} \mathrm{RCOOCH}_{3}+\mathrm{H}_{2} \mathrm{O}
$$

2.5. Transesterification of Esterified JCO. The transesterification of the esterified JCO with newly synthesized Razor shell $\mathrm{CaO}$ catalyst was carried out in a $500 \mathrm{ml}$ three-neck flat bottom glass reactor fitted together with an overhead stirrer (IKA RW 20 Digital Dual-Range Mixer, speed 60 to $500 / 240$ to $2000 \mathrm{rpm}$ ), a sampling port, and a water cooled reflex condenser. A digital hot plate was employed for providing a variable heat input as desired for the transesterification reaction process. The reactor experimental setup was immersed in a water bath to keep the uniform temperature levels throughout the reaction process. The schematic of the experimental setup is shown in Figure 1. A mix of methanol of 30 to $70 \mathrm{~mol} . / \mathrm{mol} . \%$ and Razor shell $\mathrm{CaO}$ catalyst of $1 \mathrm{wt} . \%$ to $5 \mathrm{wt} . \%$ was thoroughly mixed for one hour and then transferred to the glass reactor for each batch of experiments. The transesterification reaction was performed over discrete operating parameters that include heating temperature of $40^{\circ} \mathrm{C}$ to $60^{\circ} \mathrm{C}$, stirring speed of $500 \mathrm{rpm}$ to $700 \mathrm{rpm}$, and a reaction time of $60 \mathrm{~min}$ to $180 \mathrm{~min}$. These parametric ranges were ascertained with published literature [22-24, 49].

2.6. Design of Experiments for Optimal JME Yield. The flow of the JME yield optimization was broadly executed in four sequential operations starting with the review, experimental design, modeling and optimization, and results validation. The intrinsic actions followed in each operation stage together with decision flow are shown in Figure 2. In this study, five significant independent transesterification reaction parameters which influenced the JME yield include Razor shell $\mathrm{CaO}$ catalyst loading $(C)$, methanol to oil ratio $(M)$, reaction time $(T)$, heating temperature $(H)$, and the stirring $\mathrm{rpm}(R)$ which have been considered for the optimization of \% JME yield. The effects of five significant reaction parameters together with intrinsic interactions were devised by utilizing a central composite design (CCD) based on the half-fraction model response surface statistical model. The transesterification experimental data obtained were then fit to a full quadratic equation as specified in (5) to analyze the 


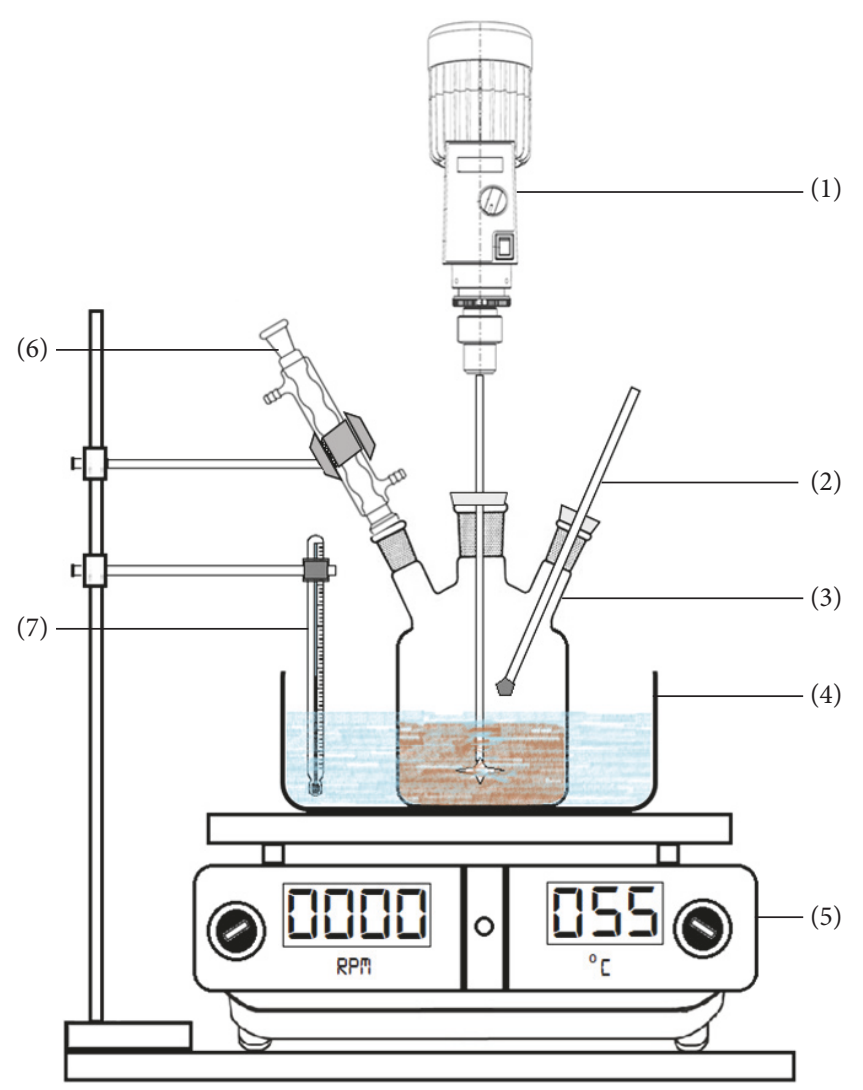

(1) Digital overhead stirrer

(2) Sampling port

(3) Three-neck glass reactor

(4) Water bath tub

FIGURE 1: Transesterification experimental setup for JME production.

response variable, \% JME yield, through the response surface regression procedure.

$$
Y=\beta_{0}+\sum_{i=1}^{n} \beta_{i} k_{i}+\sum_{i=1}^{n} \beta_{i i} k_{i}^{2}+\sum \sum_{i<j=1}^{n} \beta_{i j} k_{i} k_{j}+\varepsilon .
$$

The symbolic notations of (5) are as follows: " $Y$ " is the predicted response for \% JME yield; " $\beta_{0}$ " is the constant coefficient; " $\beta_{i}, \beta_{i i}$ and $\beta_{i j}$ " are the regression coefficients of intercept, linear, quadratic interactions; $k_{i}$ and $k_{j}$ are the coded independent process parameters; and " $\varepsilon$ " is the residual of the predicted and experimental value, known as standard error. The five significant parameters were set independently within the following ranges: $1 \leq C$ (wt. $\%) \leq 5$, $30 \leq M$ (mol./mol.\%) $\leq 70,60 \leq T$ (min) $\leq 180,40 \leq H$ $\left({ }^{\circ} \mathrm{C}\right) \leq 60$, and $500 \leq R(\mathrm{rpm}) \leq 700$. Considering each factor at five levels, 33 base experimental reaction iterations were concluded from a CCD of two-block, half-fraction model, which corresponds to sixteen cubic points, six center points in the cube, ten axial points, and one center point at the axial level. For a CCD the numerical value of alpha, $\alpha \pm 2$, is a measure of the distance that keeps each of the axial design points from the center in evolution of the factorial levels [27]. In Table 1, the actual levels of individual parameters were tabulated representing their coded and uncoded values. The redundancy in datasets and results was minimized by performing all the experiments in a random run order. The Minitab ${ }^{\circledR}$ 16.2.1 software was employed for performing the analysis of variance (ANOVA) of the model together with CCD based response surfaces generation and \% JME yield optimization. A Minitab 16.2.1 software was utilized for the response surface regression analysis and ANOVA of the designed model. The regression model was presented in (5) and validation was ensured through the confirmatory experiments, besides analysis of corresponding contour and surface plots.

2.7. Study of Razor Shell CaO Reusability, Leaching Analysis, and Transesterification with Reference Catalyst. The Razor shell $\mathrm{CaO}$ catalyst was recovered by centrifuging the transesterification reactant samples at $4000 \mathrm{rpm}$ for $60 \mathrm{~min}$. The precipitated $\mathrm{CaO}$ was then washed in four sequential repeats with $n$-hexane to remove Jatropha oil residues and then dried overnight in a forced air convection oven followed by recalcination at $850^{\circ} \mathrm{C}$ for $2 \mathrm{~h}$ before reuse. The oil portion separated was washed using double distilled deionized hot water successively for four times to clear away the traces of methanol and catalyst from the samples followed by drying over $110^{\circ} \mathrm{C}$ in order to obtain a pure JME. Furthermore, all the experiments were conducted using the variant operating parameters to investigate their specific impact on the JME yield. The biodiesel obtained from each reusability cycle was tested using an atomic absorption spectrometer-AAS (AA-7000, Shimadzu, calcium " $422.7 \mathrm{~nm}$ " hollow cathode lamps as radiation source) and to measure the amount of calcium ions $\left(\mathrm{Ca}^{2+}\right)$ concentration that leached into the JME samples. The newly synthesized Razor shell $\mathrm{CaO}$ catalytic activity was evaluated in comparison with a lab grade $\mathrm{CaO}$ (CAS.NO.0001305788). Before being used, the lab grade $\mathrm{CaO}$ catalyst was dehydrated at $105^{\circ} \mathrm{C}$ for $2 \mathrm{~h}$ in a hot air oven. Further, the reused Razor shell $\mathrm{CaO}$ catalyst surface morphology was analyzed using SEM (TM3030, Hitachi, Japan). Five successive cycles of relative transesterification were carried out using esterified JCO under similar experimental conditions and standard ratios.

2.8. Jatropha Methyl Ester Fuel Properties Analysis. The specific JME fuel properties that include density at $15^{\circ} \mathrm{C}$, calorific value, flash point, cetane value, specific gravity at $15^{\circ} \mathrm{C}$, viscosity at $40^{\circ} \mathrm{C}$, water content, ash content, acid value, monoglyceride, diglyceride, triglyceride, free glycerine, total ester content, and total glycerine contents were evaluated with a fuel property testing equipment built on the ASTM standards (D2624, D3828) and European standards (EN 14105) such as calorimeter, fuel test kit, and gas chromatograph (ShimadzuGC-2010 Plus) fitted with a flame ionization detector FID2010 Plus and a capillary column of size $30 \mathrm{~m} \times 0.25 \mathrm{~mm} \times$ $0.25 \mu \mathrm{m}$.

\section{Results and Discussion}

3.1. Analysis of Razor Shell CaO Characteristics. Thermogravimetric analysis (TGA) and differential thermal analysis 


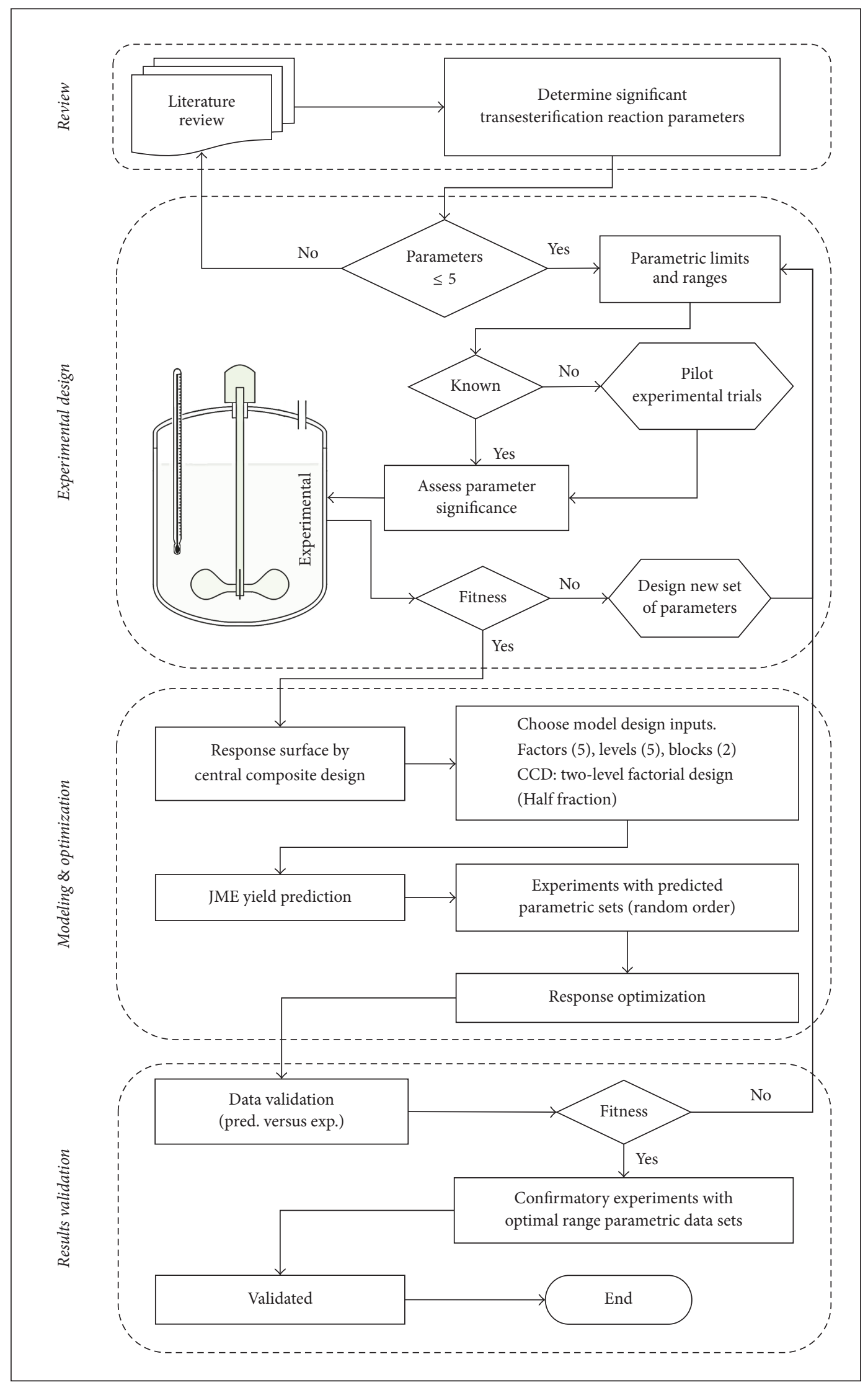

FIGURE 2: Schematic of optimal JME yield using experimental, modeling, and optimization protocol (customized based on [22]). 
TABLE 1: Factors and their uncoded levels.

\begin{tabular}{lccccc}
\hline Uncoded variable & \multirow{2}{*}{ Symbol } & -2 & -1 & Levels & 0 \\
\hline Razor shell CaO catalyst loading (wt.\%) & $C$ & 1 & 2 & 3 & 1 \\
Methanol to oil ratio (mol./mol.\%) & $M$ & 30 & 40 & 50 & 4 \\
Reaction time (min) & $T$ & 60 & 90 & 60 & 70 \\
Heating temperature $\left({ }^{\circ} \mathrm{C}\right)$ & $H$ & 40 & 45 & 50 & 120 \\
Stirring speed $(\mathrm{rpm})$ & $R$ & 500 & 550 & 600 & 55 \\
\hline
\end{tabular}

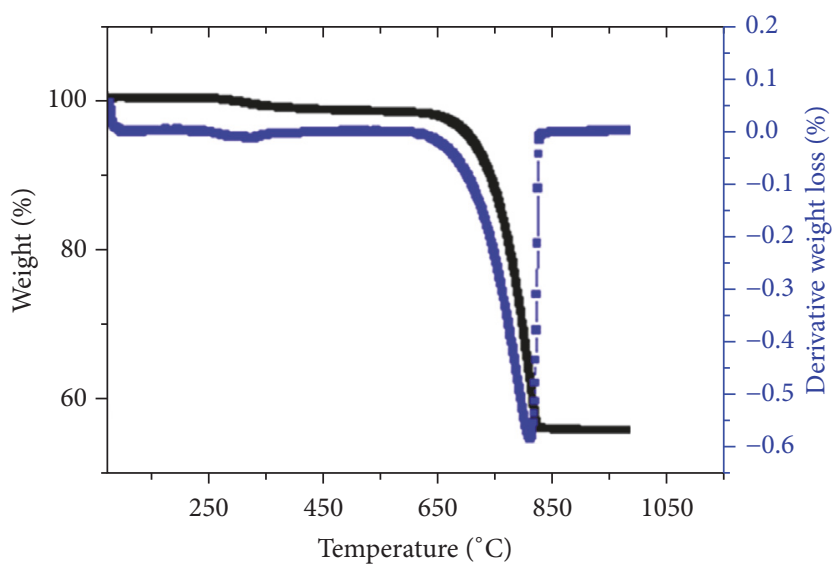

FIGURE 3: Thermal analysis (TGA/DTA) of Razor shells.

(DTA) of uncalcined Razor shell were shown in Figure 3. The weight loss indicates quantitative composition of Razor shell catalyst. Also, the exothermic and endothermic measurements presented using DTA curve which shows thermal influence on oxidation degradation and physiochemical changes. From Figure 3 till $650^{\circ} \mathrm{C}$, TGA curve continued constant and then decomposition initiated over $850^{\circ} \mathrm{C}$. A sharp TGA slope between $650^{\circ} \mathrm{C}$ and $850^{\circ} \mathrm{C}$ is observed which conforms $\mathrm{CaCO}_{3}$ thermal decomposition. Further, DTA curve is consistent with TGA and at a temperature of $820^{\circ} \mathrm{C}$, DTA indicates $\mathrm{CaCO}_{3}$ endothermic conversion to a constant $\mathrm{CaO}$. Therefore, the TGA/DTA analysis confirms calcination of Razor shells over temperature range of $850^{\circ} \mathrm{C}$ to convert $\mathrm{CaCO}_{3}$ to $\mathrm{CaO}$. This result is in agreement with Tan et al. [14] and Roschat et al. [50].

The infrared spectra of Razor shell synthesized $\mathrm{CaO}$ and lab grade $\mathrm{CaO}$ powder samples are shown in Figure 4. The absorption bands over wavelength $<700 \mathrm{~cm}^{-1}$ were strong besides broad medium absorption bands at $990 \mathrm{~cm}^{-1}$, $1430 \mathrm{~cm}^{-1}$, and $3640 \mathrm{~cm}^{-1}$ which attributes presence of $\mathrm{Ca}-\mathrm{O}$ stretching. According to the reports of Tan et al. [14], McDevitt and Baun [51], Nasrazadani and Eureste [52], and Zaki et al. [53], the strong IR spectral absorption over wavelengths $400 \mathrm{~cm}^{-1}$ and $290 \mathrm{~cm}^{-1}$ signifies $\mathrm{Ca}-\mathrm{O}$ which confirms $\mathrm{CaO}$ presence. Further, weak absorption wavelengths $>3700 \mathrm{~cm}^{-1}$ specifically $3722 \mathrm{~cm}^{-1}$ and $3807 \mathrm{~cm}^{-1}$ were present due to carbonyl " $\mathrm{C}=\mathrm{O}$ " and hydroxyl " $\mathrm{O}-\mathrm{H}$ " groups asymmetric bending. As reported by De Sousa et al. [21], Tan et al. [14], and Margaretha et al. [19], the hygroscopic nature of catalyst is highly prone to absorb carbon dioxide and moisture

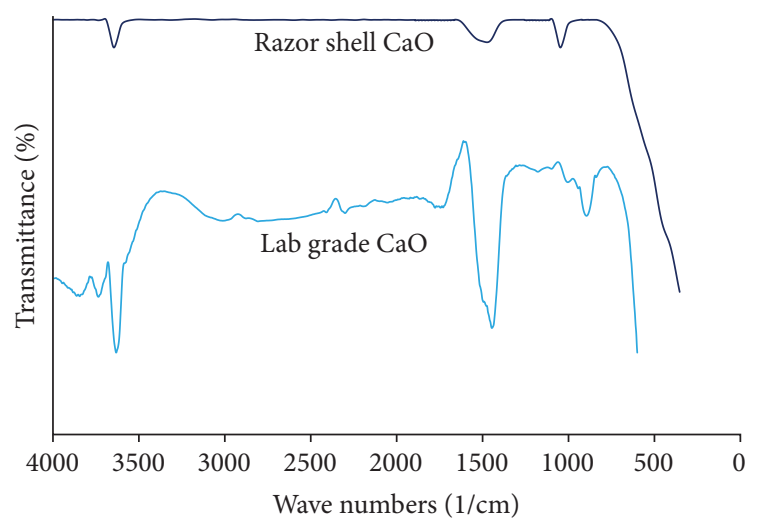

FIGURE 4: IR spectra of calcined lab grade $\mathrm{CaO}$ and Razor shell $\mathrm{CaO}$.

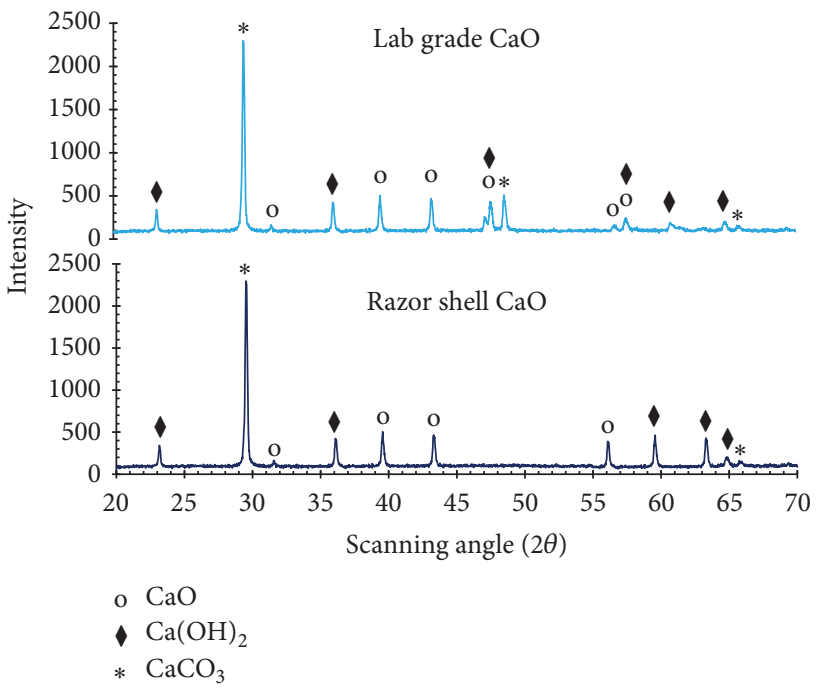

FIGURE 5: XRD spectral graph of analysis of calcined lab grade $\mathrm{CaO}$ and Razor shell $\mathrm{CaO}$.

from the atmosphere and subsequently forms $\mathrm{CaCO}_{3}$ and $\mathrm{Ca}(\mathrm{OH})_{2}$.

The crystalline structural information of Razor shell synthesized $\mathrm{CaO}$ and lab grade $\mathrm{CaO}$ obtained from XRD analysis is shown in Figure 5. The Razor shell synthesized $\mathrm{CaO}$ XRD spectral graph shows clear diffraction peaks at scanning angles $(2 \theta)$ of $23.18^{\circ}, 29.54^{\circ}, 36.14^{\circ}, 39.56^{\circ}$, $43.28^{\circ}, 56.16^{\circ}, 59.54^{\circ}$, and $63.34^{\circ}$, whereas lab grade $\mathrm{CaO}$ shows peaks at $23.18^{\circ}, 29.54^{\circ}, 36.14^{\circ}, 39.56^{\circ}, 43.28^{\circ}, 47.2^{\circ}$, $47.68^{\circ}, 48.68^{\circ}, 56.16^{\circ}, 56.94^{\circ}, 57.58^{\circ}, 59.54^{\circ}, 61.08^{\circ}$, and 


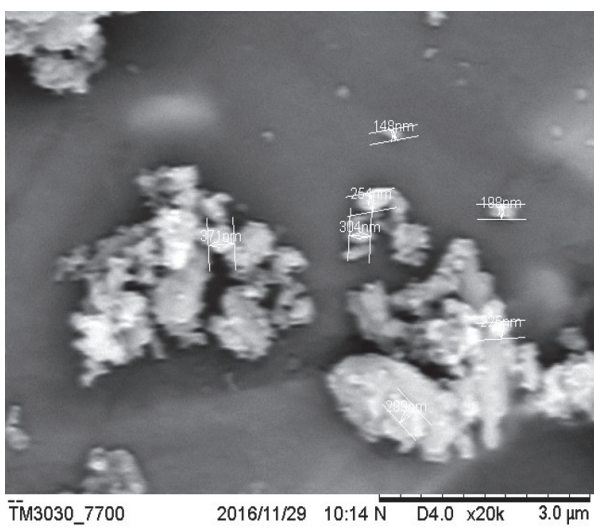

(a)

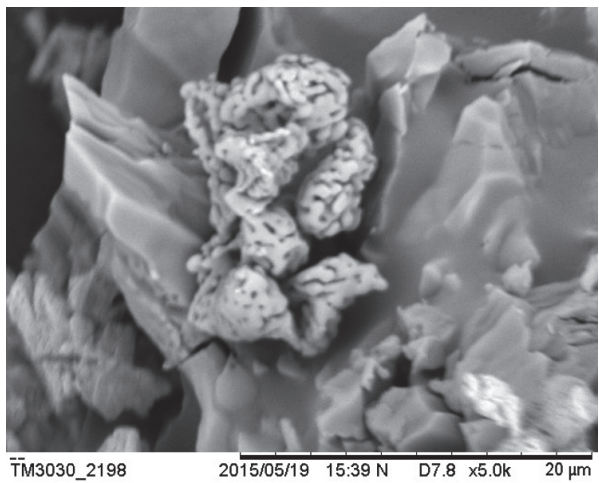

(c)

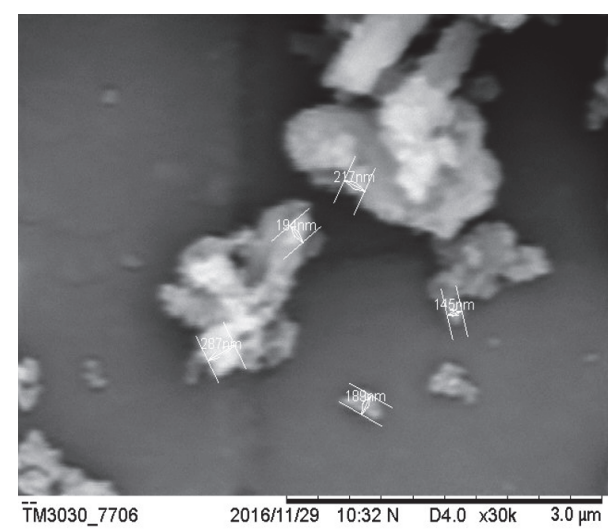

(b)

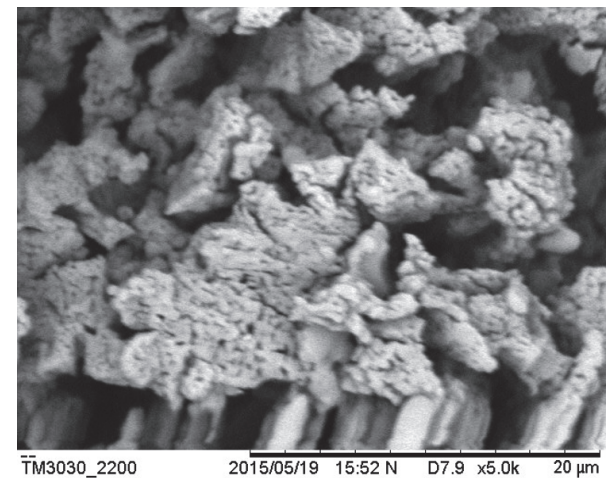

(d)

Figure 6: SEM monograms of (a, b) hydro aerated calcined Razor shell CaO; (c, d) calcined lab grade $\mathrm{CaO}$.

$63.34^{\circ}$. The diffraction patterns were verified and consistent according to JCPDS file number 00-037-1497 as well with published reports by Mirghiasi et al. [54], Teo et al. [55], Chen et al. [56], De Sousa et al. [21], and Tan et al. [14]. The "calcination-hydro aeration-dehydration" resulted in removal hydroxyl and carbonyl phases and causes of a pure $\mathrm{CaO}$. However after thermal decomposition high hygroscopic nature of calcium and minor moisture absorption at lab temperature cause formation of a few $\mathrm{Ca}(\mathrm{OH})_{2}$. According to Scherrer's equation calculations the average crystalline sixe of Razor shell $\mathrm{CaO}$ is noted as $87.2 \mathrm{~nm}$.

The SEM surface morphology of hydro aerated and calcined Razor shell $\mathrm{CaO}$ was measured at a microscopic magnification of $20000 \mathrm{x}$ and $30000 \mathrm{x}$ with $0.3 \mu \mathrm{m}$, shown in Figures 6(a) and 6(b). The SEM monograms of calcined lab grade $\mathrm{CaO}$ surface morphology were viewed at a magnification of 5000x shown in Figures 6(c) and 6(d). The Razor shell CaO SEM monograms encompass a number of particles in regular sizes of $145 \mathrm{~nm}-371 \mathrm{~nm}$ together with agglomerates observed. This can be attributed to structural changes of isolated isotropic calcium oxide particles after hydro aeration followed by calcined at high temperatures while $\mathrm{CaCO}_{3}$ constituents decompose into $\mathrm{CaO}$ and $\mathrm{CO}_{2}$, as a result of decreases in particle sizes. These results are fully in accordance with investigation reports of Tan et al. [14] and Buasri et al. [10].
The BET and BJH analysis of Razor shell synthesized, hydro aerated, and nonaerated calcined $\mathrm{CaO}$ and uncalcined Razor shell together with reference catalyst samples had determined $S_{\mathrm{BET}}$ of $92.63 \mathrm{~m}^{2} / \mathrm{g}, 85.27 \mathrm{~m}^{2} / \mathrm{g}, 5.21 \mathrm{~m}^{2} / \mathrm{g}$, and $36.6 \mathrm{~m}^{2} / \mathrm{g}$; pore diameters of $37.311 \mathrm{~nm}, 33.342 \mathrm{~nm}, 11.355 \mathrm{~nm}$, and $13.861 \mathrm{~nm}$; and also total pore volume of $0.613 \mathrm{cc} / \mathrm{g}$, $0.423 \mathrm{cc} / \mathrm{g}, 0.0121 \mathrm{cc} / \mathrm{g}$, and $0.126 \mathrm{cc} / \mathrm{g}$, respectively. Compared to literature reports, Tan et al. [14] derived calcium catalyst from chicken-eggshells $\left(54.6 \mathrm{~m}^{2} / \mathrm{g}\right)$ and ostricheggshells $\left(71.0 \mathrm{~m}^{2} / \mathrm{g}\right)$; Buasri et al. [10] synthesized mussel shells $\left(89.91 \mathrm{~m}^{2} / \mathrm{g}\right)$, cockle shells $\left(59.87 \mathrm{~m}^{2} / \mathrm{g}\right)$, and scallop shells (74.96 m²/g), while Margaretha et al. [19] reported CaO of $17 \mathrm{~m}^{2} / \mathrm{g}$. The $S_{\mathrm{BET}}$ of Razor shell $\mathrm{CaO}$ is relatively high; moreover, the resulted pore diameter ranges within mesopores $(2 \mathrm{~nm}-50 \mathrm{~nm})$ demonstrate high value of the catalyst surface area together with their suitability for adsorption, catalytic, and energy storage applications [57]. Hence, the $\mathrm{CaO}$ of Razor shells synthesized through "calcination-hydro aeration-dehydration" is an active catalyst owing to high pores and external surface area. Further, the Razor shell synthesized $\mathrm{CaO}$ particles demonstrated bimodal particle sizes (Figure 7). The particle sizes of hydro aerated calcined Razor shell $\mathrm{CaO}$ are in the range of $0.82 \mu \mathrm{m}-5.55 \mu \mathrm{m}$ with a mean particle size of $2.97 \mu \mathrm{m}$; meanwhile the nonaerated calcined Razor shell $\mathrm{CaO}$ showed particle sizes over $0.8 \mu \mathrm{m}-9.25 \mu \mathrm{m}$ and mean size of $4.37 \mu \mathrm{m}$. The difference 


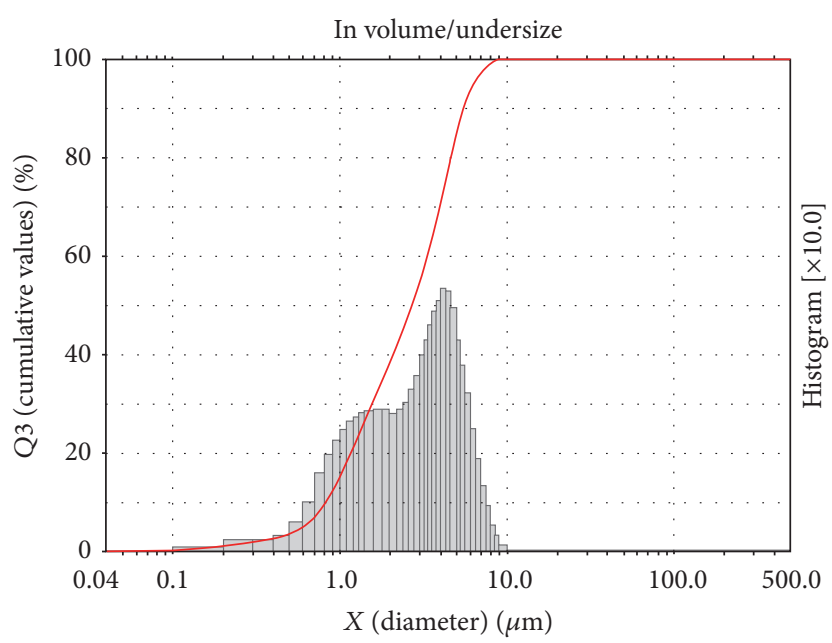

(a)

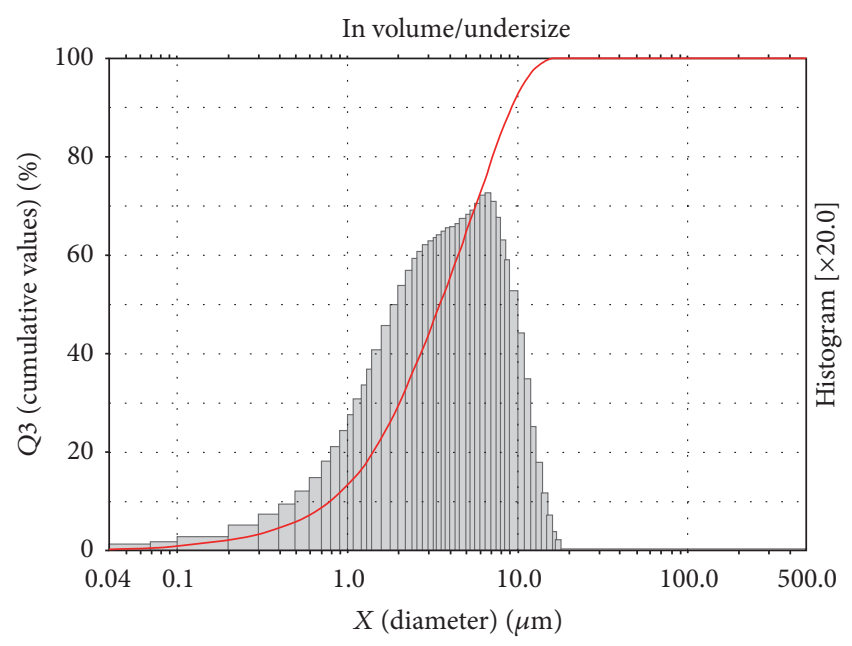

(b)

FIgURE 7: Particle size distribution grid of (a) hydro aerated calcined Razor shell CaO; (b) nonaerated calcined Razor shell CaO.

in mean and median particle sizes of hydro aerated and nonaerated calcined Razor shell $\mathrm{CaO}$ is significant. Therefore the "calcination-hydro aeration-dehydration" caused a mix of micro- and nanocatalyst particles together with few large agglomerates. The results are comparable and consistent with the literature reports of Tan et al. [14] and Kesić et al. [58]. By adding Hammett indicators to Razor shell synthesized $\mathrm{CaO}$, the catalyst samples successfully changed the color of phenolphthalein $\left(\mathrm{H}_{-}=8.2\right)$ from being colorless to pink, thymolphthalein $\left(\mathrm{H}_{-}=10.0\right)$ from being colorless to blue, and 2,4-dinitroaniline $\left(\mathrm{H}_{-}=15.0\right)$ from yellow to mauve, respectively. Conversely, the catalyst was unsuccessful to change the color of 4-nitroaniline $\left(\mathrm{H}_{-}=18.4\right)$. Hence, the newly synthesized $\mathrm{CaO}$ catalyst basic strength was labeled as $15<\mathrm{H}_{-}<18.4$ and therefore the basic strength of newly synthesized $\mathrm{CaO}$ catalyst was a strong basicity for JCO. The basicity of Razor shell $\mathrm{CaO}$ agreed with the published results for $\mathrm{CaO}$, synthesized from waste materials $[15,43$, 44]. The Razor shell $\mathrm{CaO}$ catalyst was synthesized following "calcination-hydro aeration-dehydration" protocol which resulted in smaller particle size as well as greater surface area. According to Thiele [59], Buasri et al. [10], and Teo et al. [8] catalyst of higher surface area and lesser particle size improves its catalytic activity and reaction kinetics rapidly by refining the particle diffusion drawbacks. Henceforth the Razor shell $\mathrm{CaO}$ is labeled as "an active catalyst."

3.2. Jatropha Methyl Ester Production Analysis. The JME was produced by transesterification of esterified JCO using methanol and Razor shell $\mathrm{CaO}$ catalyst and, in addition, three controlled parameters such as reaction time, heating temperature, and stirring rpm. The minimum FFA condition from the acid esterification was opted for Razor shell $\mathrm{CaO}$ catalyzed transesterification of Jatropha triglycerides. The standard protocol comprising experimental, modeling and optimization, and validation operation processes as presented in Figure 2 was followed in order. The selection of optimal experimental parametric values was determined on the basis of their relative impact evaluations while optimizing the JME yield, which is discussed in the following sections.

3.3. Regression Model Analysis. The experimental results of second step pf transesterification reaction were analyzed using a two-block, half-fraction CCD statistical model as tabulated in Table 2. The estimated response surface regression coefficients for optimal JME using the uncoded units are as listed in Table 3. A regression modal equation that was fitting the JME yield as a response parameter to the other five significant reaction parameters in terms of their uncoded values is as given in

$$
\begin{aligned}
Y= & 100.071+0.262 C+6.707 M+4.002 T+4.515 H \\
& +0.931 R-11.439 C^{2}-14.186 M^{2}-14.224 T^{2} \\
& -11.824 H^{2}-6.524 R^{2}+4.379 C M+0.493 C T \\
& -0.846 C H-0.193 C R-2.021 M T-4.479 M H \\
& +0.721 M R-1.393 T H+3.754 T R-1.707 H R .
\end{aligned}
$$

The sign of regression coefficient is an indication of the effect of the corresponding term being synergetic or antagonistic, on the response parameter. Referring to the mathematical equation (6) all the five parameters in their linear form show a positive effect, whereas the quadratic terms of these parameters have a negative effect on the JME yield. However, the ten interaction terms have a mix of both positive and negative effects on the JME yield, which will be discussed in the later part of this section, in detail.

The regression modal analysis of variance (ANOVA) was utilized to study the adequacy of the model [60]. Table 4 summarizes the ANOVA for the model designed. The value of the coefficient of determination $R^{2}$ for the model was noted as $95.81 \%$, which implies the fitness of the regression model in attributing good correlation between the percentage of JME yield and five transesterification parameters studied [61], 
TABLE 2: The CCD design matrix for JME yield prediction (randomized).

\begin{tabular}{|c|c|c|c|c|c|c|c|c|c|}
\hline \multirow{2}{*}{ Type of points and runs } & \multirow{2}{*}{ Run } & \multirow{2}{*}{ Block } & \multicolumn{5}{|c|}{ Coded parameters } & \multicolumn{2}{|c|}{ JME yield } \\
\hline & & & C & $M$ & $T$ & $H$ & $R$ & Predict. & Exp. \\
\hline \multirow{16}{*}{ Cubic points $\alpha= \pm 1$ (16 runs) } & 1 & 1 & 1 & -1 & -1 & -1 & -1 & 74.81 & 74.40 \\
\hline & 2 & 1 & 1 & 1 & 1 & 1 & 1 & 73.52 & 72.40 \\
\hline & 3 & 1 & 1 & -1 & 1 & -1 & 1 & 82.58 & 83.40 \\
\hline & 4 & 1 & 1 & -1 & -1 & 1 & 1 & 85.47 & 85.60 \\
\hline & 5 & 1 & 1 & -1 & 1 & 1 & -1 & 78.76 & 77.80 \\
\hline & 6 & 1 & 1 & 1 & 1 & -1 & -1 & 80.80 & 79.60 \\
\hline & 7 & 1 & 1 & 1 & -1 & 1 & -1 & 88.26 & 89.00 \\
\hline & 8 & 1 & -1 & 1 & 1 & 1 & -1 & 87.36 & 86.40 \\
\hline & 9 & 1 & 1 & 1 & -1 & -1 & 1 & 83.90 & 83.20 \\
\hline & 10 & 1 & -1 & -1 & -1 & 1 & -1 & 79.14 & 78.20 \\
\hline & 11 & 1 & -1 & 1 & -1 & 1 & 1 & 87.21 & 89.20 \\
\hline & 12 & 1 & -1 & -1 & -1 & -1 & 1 & 88.71 & 89.00 \\
\hline & 13 & 1 & -1 & 1 & -1 & -1 & -1 & 87.78 & 87.00 \\
\hline & 14 & 1 & -1 & -1 & 1 & -1 & -1 & 84.08 & 82.60 \\
\hline & 15 & 1 & -1 & -1 & 1 & 1 & 1 & 90.09 & 91.00 \\
\hline & 16 & 1 & -1 & 1 & 1 & -1 & 1 & 91.59 & 91.80 \\
\hline \multirow{10}{*}{ Axial points $\alpha= \pm 2$ (10 runs) } & 17 & 2 & -2 & 0 & 0 & 0 & 0 & 90.19 & 87.20 \\
\hline & 18 & 2 & 2 & 0 & 0 & 0 & 0 & 90.71 & 93.40 \\
\hline & 19 & 2 & 0 & 0 & 0 & -2 & 0 & 81.00 & 84.00 \\
\hline & 20 & 2 & 0 & 0 & -2 & 0 & 0 & 94.41 & 93.00 \\
\hline & 21 & 2 & 0 & -2 & 0 & 0 & 0 & 83.66 & 83.20 \\
\hline & 22 & 2 & 0 & 0 & 0 & 0 & 2 & 91.67 & 93.00 \\
\hline & 23 & 2 & 0 & 2 & 0 & 0 & 0 & 85.55 & 86.60 \\
\hline & 24 & 2 & 0 & 0 & 0 & 0 & -2 & 94.58 & 94.40 \\
\hline & 25 & 2 & 0 & 0 & 2 & 0 & 0 & 94.44 & 95.60 \\
\hline & 26 & 2 & 0 & 0 & 0 & 2 & 0 & 96.30 & 96.00 \\
\hline \multirow{6}{*}{ Center points in cube $\alpha=0$ ( 6 runs) } & 27 & 1 & 0 & 0 & 0 & 0 & 0 & 98.25 & 98.00 \\
\hline & 28 & 1 & 0 & 0 & 0 & 0 & 0 & 98.25 & 98.00 \\
\hline & 29 & 1 & 0 & 0 & 0 & 0 & 0 & 95.26 & 97.60 \\
\hline & 30 & 1 & 0 & 0 & 0 & 0 & 0 & 95.26 & 97.60 \\
\hline & 31 & 1 & 0 & 0 & 0 & 0 & 0 & 98.25 & 98.00 \\
\hline & 32 & 1 & 0 & 0 & 0 & 0 & 0 & 98.25 & 97.80 \\
\hline Center points in axial (1 run) & 33 & 2 & 0 & 0 & 0 & 0 & 0 & 99.89 & 98.00 \\
\hline
\end{tabular}

and also to confess the successful integrity of the regression equation among the experimental data, appropriately. The difference between the coefficients of determination $\left(R^{2}\right)$ and the correlation $\left(R_{\text {adj }}^{2}=87.81 \%\right)$ at large discloses the presence of the nonsignificant parametric terms in the designed regression model. The comparative graph of Figure 9 shows coherence between JME predicted and experimental yields. Besides, the $f$-test and $P$ values were the indications of modal and each regression coefficient significance, respectively [30].

\subsection{Transesterification Reaction Parameter Effects Analysis on} JME Yield. Each of the five transesterification parameters' significance and their effect on JME yield were tested and analyzed in terms of their parametric interactions through the regression model (6) as well as the ANOVA. From the data reported in Table 4, the linear form of the parametric terms of methanol to oil ratio $(M)$, reaction time $(T)$, and heating temperature $(H)$ was having relatively higher impact on the JME yield owing to the high $F$-values as compared to the other parameters catalyst loading $(C)$ and stirring rpm $(R)$. The interaction between any two selected parameters on $\%$ JME yield was analyzed by holding the remaining three reaction parameters at their median levels.

3.4.1. Catalyst Loading (C). Catalyst loading is one of the key parameters that influence the production of JME in terms of both JME yield percentage and its quality [62-64]. The effect of the Razor shell $\mathrm{CaO}$ catalyst loading interactions with other reaction parameters of the reaction time, methanol to oil ratio, heating temperature, and stirring speed was plotted, respectively, in the contour plots shown in Figures $8(\mathrm{a}), 8(\mathrm{~b}), 8(\mathrm{c})$, and $8(\mathrm{~d})$. Though the catalyst loading was carried through $1 \mathrm{wt} . \%-5 \mathrm{wt} . \%$, JME yield was significant, ">98\%" over 2 wt.\%-4 wt.\%. From the regression equation 
TABLE 3: Estimated response surface regression coefficients for optimal JME yield using uncoded units.

\begin{tabular}{|c|c|c|c|c|}
\hline Term & Coef. & SE coef. & $T$ & $P$ \\
\hline Constant & 100.071 & 1.0485 & 95.447 & 0.000 \\
\hline Block & -1.819 & 0.4824 & -3.771 & 0.003 \\
\hline \multicolumn{5}{|l|}{ Linear } \\
\hline C & 0.262 & 1.0603 & 0.247 & 0.810 \\
\hline$M$ & 6.707 & 1.1903 & 5.635 & 0.000 \\
\hline$T$ & 4.002 & 1.0721 & 3.733 & 0.003 \\
\hline$H$ & 4.515 & 1.0907 & 4.140 & 0.002 \\
\hline$R$ & 0.931 & 1.0721 & 0.868 & 0.404 \\
\hline \multicolumn{5}{|l|}{ Quadratic } \\
\hline$C^{2}$ & -11.439 & 1.9574 & -5.844 & 0.000 \\
\hline$M^{2}$ & -14.186 & 1.9517 & -7.269 & 0.000 \\
\hline$T^{2}$ & -14.224 & 1.9047 & -7.468 & 0.000 \\
\hline$H^{2}$ & -11.824 & 1.9047 & -6.208 & 0.000 \\
\hline$R^{2}$ & -6.524 & 1.9047 & -3.425 & 0.006 \\
\hline \multicolumn{5}{|c|}{ Interaction } \\
\hline$C \times M$ & 4.379 & 3.0693 & 1.427 & 0.181 \\
\hline$C \times T$ & 0.493 & 2.6488 & 0.186 & 0.856 \\
\hline$C \times H$ & -0.846 & 2.7161 & -0.312 & 0.761 \\
\hline$C \times R$ & -0.193 & 2.6488 & -0.073 & 0.943 \\
\hline$M \times T$ & -2.021 & 3.0062 & -0.672 & 0.515 \\
\hline$M \times H$ & -4.479 & 3.0693 & -1.459 & 0.172 \\
\hline$M \times R$ & 0.721 & 3.0062 & 0.240 & 0.815 \\
\hline$T \times H$ & -1.393 & 2.6488 & -0.526 & 0.609 \\
\hline$T \times R$ & 3.754 & 2.7161 & 1.382 & 0.194 \\
\hline$H \times R$ & -1.707 & 2.6488 & -0.645 & 0.532 \\
\hline
\end{tabular}

(6), it is evident that the catalyst loading has a positive impact on the JME yield; that is, JME yield was proportional to the utilization of $1 \mathrm{wt} . \%-4 \mathrm{wt} . \%$ catalyst. It was noted that the lower catalyst loading $(<2 \mathrm{wt} . \%)$ does not result in a productive JME yield. Furthermore, the higher catalyst loading (>4 wt.\%) leads to the catalyst secondary reactions with other reactants which result in the reduction of JME yield [65]. The calcium based catalysts have demonstrated leaching tendency to the biodiesels during transesterification $[12,46$, 47]. According to the biodiesel standards, EN 14214:2008, allowable concentration of group-I $(\mathrm{Na}+\mathrm{K})$ and groupII $(\mathrm{Ca}+\mathrm{Mg})$ is max. $5.0 \mathrm{mg} / \mathrm{kg}$ in the biodiesel samples while the residues of excess metal oxides act as impurities in the biodiesel fuel produced [66]. The catalyst loading interactions with methanol to the oil ratio $(C \times M)$ and transesterification reaction time $(C \times T)$ resulted in positive interactions. In contrast, interactions with reactants heating temperature $(C \times H)$ and stirring speed $\mathrm{rpm}(C \times R)$ have alleviated the JME yield. Among all, $(C \times M)$ with regression coefficient " +4.379 " demonstrated the highest effect impact in accelerating the transesterification reaction kinetics for the catalyst loading $2 \mathrm{wt} . \%-4 \mathrm{wt} . \%$ and about $46-65 \mathrm{~mol} . / \mathrm{mol} . \%$, Figure 8(b), leading to “>98\%" JME yield $[67,68]$.

3.4.2. Methanol to Oil Ratio (M). Methanol to oil ratio is a primary reactant parameter in the transesterification of VO. The methanol to oil ratio is determined in correlation with a type of $\mathrm{VO}$, catalyst, and other reaction conditions. Figures $8(\mathrm{~b}), 8(\mathrm{e}), 8(\mathrm{f})$, and $8(\mathrm{~g})$ present the methanol to oil molar ratio with catalyst loading, reaction time, heating temperature, and stirring speed interactions, respectively. The JME yield of $\geq 98 \%$ was reported on to $46^{\circ} \mathrm{C} \pm 11^{\circ} \mathrm{C}-56^{\circ} \mathrm{C} \pm$ $1^{\circ} \mathrm{C}$ operating temperatures. According to the stoichiometric estimations, $30: 1 \mathrm{~mole} / \mathrm{mole} \%$ methanol to JCO ratio is required [69]; however, in actual esterification experiments a critical methanol to oil ratio which ranges from $30: 1$ to $210: 1$ $\mathrm{mol} . / \mathrm{mol} . \%$ was reported to carry out complete reaction, that is, transformation of JCO triglycerides into the JME and glycerin. The linear regression coefficient of methanol to oil ratio $(M)$ in the regression equation (6) " +6.707 " refers to its greater influence on transformation reaction process as well as on optimal JME yield\%. Although experiments were performed over a range $30 \leq M(\mathrm{~mol} . / \mathrm{mol} . \%) \leq 70$, lower JME yield\% results were noted for $<50 \mathrm{~mol} . / \mathrm{mol} . \%$ of methanol to oil ratio; this may be due to the insufficient amount of methanol under the reaction conditions set forth, while $50-60 \mathrm{~mol} . / \mathrm{mol} . \%$ methanol maximum transformation was achieved relatively compared to the molar ratio which was $60-70 \mathrm{~mol} . / \mathrm{mol} . \%$ which indicates keeping the excessive amount of methanol hampers in achieving the reaction equilibrium as well as biodiesel cost economics [62]. The methanol to oil ratio interaction with the stirring speed $(M \times R)$ resulted as a positive response. This may be due to increase in the catalytic and transesterification 
TABLE 4: Analysis of variance for optimal JME.

\begin{tabular}{|c|c|c|c|c|c|c|}
\hline Source & DF & Sum of squares & Adj. sum of squares & Adj. mean of squares & $F$ & $P$ \\
\hline Blocks & 1 & 99.90 & 94.69 & 94.694 & 14.22 & 0.0030 \\
\hline Regression & 20 & 1575.49 & 1575.49 & 78.775 & 11.83 & $<0.0001$ \\
\hline Linear & 5 & 632.77 & 393.59 & 78.717 & 11.82 & $<0.0001$ \\
\hline$C$ & 1 & 11.15 & 0.41 & 0.405 & 0.06 & 0.8100 \\
\hline$M$ & 1 & 328.66 & 211.45 & 211.452 & 31.75 & $<0.0001$ \\
\hline$T$ & 1 & 101.68 & 92.8 & 92.800 & 13.94 & 0.0030 \\
\hline$H$ & 1 & 187.28 & 114.13 & 114.130 & 17.14 & 0.0020 \\
\hline$R$ & 1 & 4.00 & 5.02 & 5.021 & 0.75 & 0.4040 \\
\hline Square & 5 & 902.29 & 914.24 & 182.849 & 27.46 & $<0.0001$ \\
\hline$C^{2}$ & 1 & 79.02 & 227.41 & 227.414 & 34.15 & $<0.0001$ \\
\hline$M^{2}$ & 1 & 223.77 & 351.83 & 351.831 & 52.83 & $<0.0001$ \\
\hline$T^{2}$ & 1 & 301.16 & 371.36 & 371.356 & 55.77 & $<0.0001$ \\
\hline$H^{2}$ & 1 & 227.14 & 256.61 & 256.608 & 38.53 & $<0.0001$ \\
\hline$R^{2}$ & 1 & 71.19 & 78.12 & 78.117 & 11.73 & 0.0060 \\
\hline Interaction & 10 & 40.43 & 40.43 & 4.043 & 0.61 & 0.7800 \\
\hline$C \times M$ & 1 & 6.70 & 13.55 & 13.552 & 2.04 & 0.1810 \\
\hline$C \times T$ & 1 & 0.02 & 0.23 & 0.231 & 0.03 & 0.8560 \\
\hline$C \times H$ & 1 & 3.35 & 0.65 & 0.647 & 0.1 & 0.7610 \\
\hline$C \times R$ & 1 & 0.02 & 0.04 & 0.035 & 0.01 & 0.9430 \\
\hline$M \times T$ & 1 & 3.01 & 3.01 & 3.011 & 0.45 & 0.5150 \\
\hline$M \times H$ & 1 & 9.27 & 14.18 & 14.179 & 2.13 & 0.1720 \\
\hline$M \times R$ & 1 & 0.48 & 0.38 & 0.383 & 0.06 & 0.8150 \\
\hline$T \times H$ & 1 & 2.08 & 1.84 & 1.841 & 0.28 & 0.6090 \\
\hline$T \times R$ & 1 & 12.72 & 12.72 & 12.718 & 1.91 & 0.1940 \\
\hline$H \times R$ & 1 & 2.77 & 2.77 & 2.766 & 0.42 & 0.5320 \\
\hline Residual error & 11 & 73.25 & 73.25 & 6.659 & & \\
\hline Lack-of-fit & 7 & 73.22 & 73.22 & 10.460 & 1394.68 & $<0.0001$ \\
\hline Pure error & 4 & 0.03 & 0.03 & 0.008 & & \\
\hline Total & 32 & 1748.64 & & & & \\
\hline
\end{tabular}

kinetics as a whole with the stirring speed and hence there is a proportional increase in the \% JME yield together with methanol to oil ratio. On the other hand, methanol interactions with parameters heating temperature $(M \times H$ : $-4.479)$ and reaction time $(M \times T:-2.021)$ were marked as highly negative on the response surface, that is, \% JME yield. This is due to the reason that the reactant heating temperatures are close to the methanol boiling point $\left(64.7^{\circ} \mathrm{C}\right)$ leading to continuous and rapid evaporation of methanol and hence lesser availability of the methanol for completing the transesterification [70].

3.4.3. Transesterification Reaction Time (T). The requisite duration of reaction time for catalyzed transesterification is governed by factors such as catalyst type, degree of temperature, and also reactants mixing $\mathrm{rpm}[70,71]$. The effects of transesterification reaction time on JME yield\% were investigated in conjunction with catalyst loading, methanol to oil ratio, heating temperature, and stirring speed parameter interactions. The analysis of experimental results is showed graphically in Figures 8(a), 8(e), 8(h), and 8(i) and statistically from (6), the highest significance for interactions of the reaction time and stirring speed $(T \times R)$ over interactions $(C \times T),(T \times H)$, and $(M \times T)$ confesses through their regression coefficients “+3.753," “+0.493," “-1.393," and “-2.021," respectively. At the beginning of the transesterification, a passive rate of reaction phase was observed due to the gradual dispersion of methanol into the glycerides in JCO $[70,72]$. As the reaction time increases, the amount of triglycerides conversion into ME besides JME yield\% was also raised. Normally, across the operational reaction time, the "110 $\pm 5 \mathrm{~min}-150 \pm 5 \mathrm{~min}$ " transesterification iterations results revealed a JME yield of " $\geq 98 \%$." Beyond these reaction duration levels a notable decline in JME yield\% was reported. This may be due to the fact that extended reaction timings lead to reversible reactions (1)-(3) which result in continual ester content fall besides soap and diglyceroxide formation $[70,73,74]$. Both methanol to oil ratio and temperature were showing unfavorable interactions with reaction time. Hence, an appropriate reaction time was maintained.

3.4.4. Heating Temperature $(H)$. The transesterification reaction kinetics was significantly affected by the reactants heating temperature [3]. Figures 8(c), 8(f), 8(h), and 8(j) present 

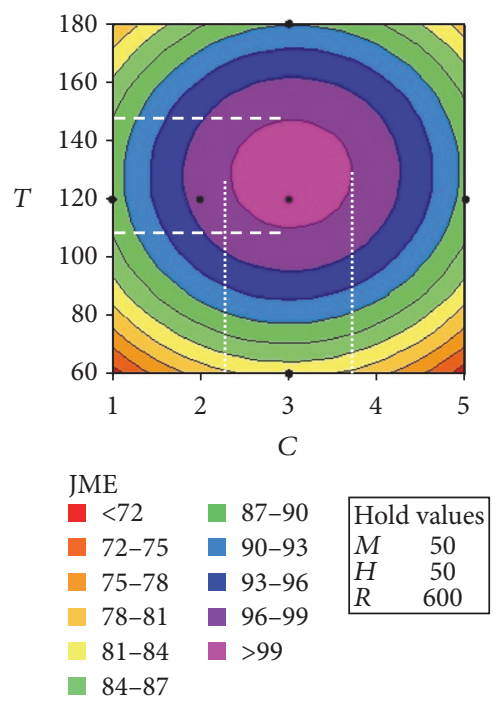

(a) Reaction time and catalyst concentration $(T \times C)$
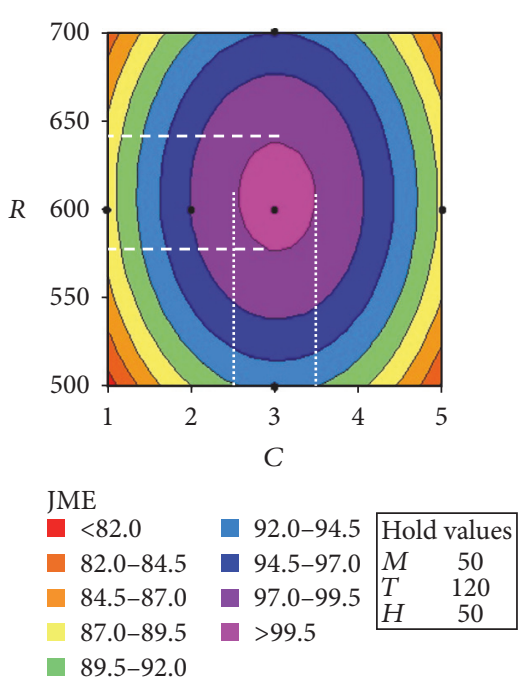

(d) Stirring speed and catalyst concentration $(R \times C)$
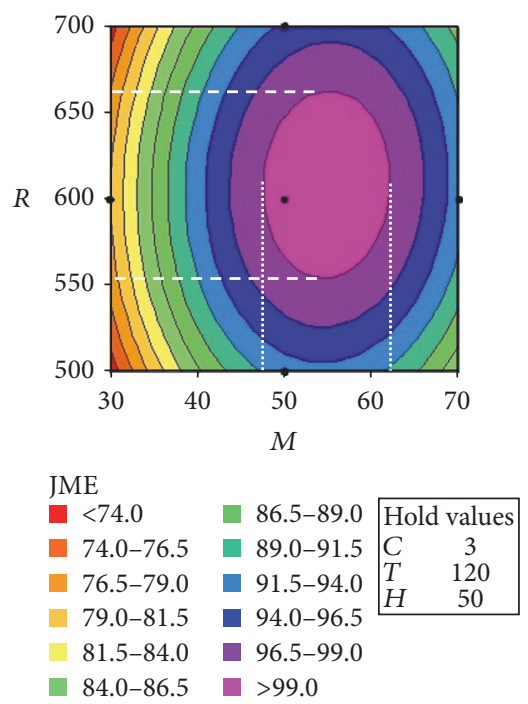

(g) Stirring speed and methanol to oil ratio $(R \times M)$
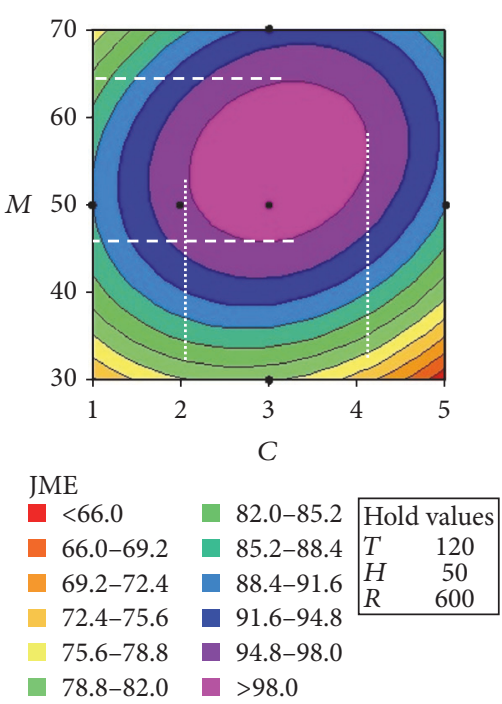

(b) Methanol to oil ratio and catalyst concentration $(M \times C)$
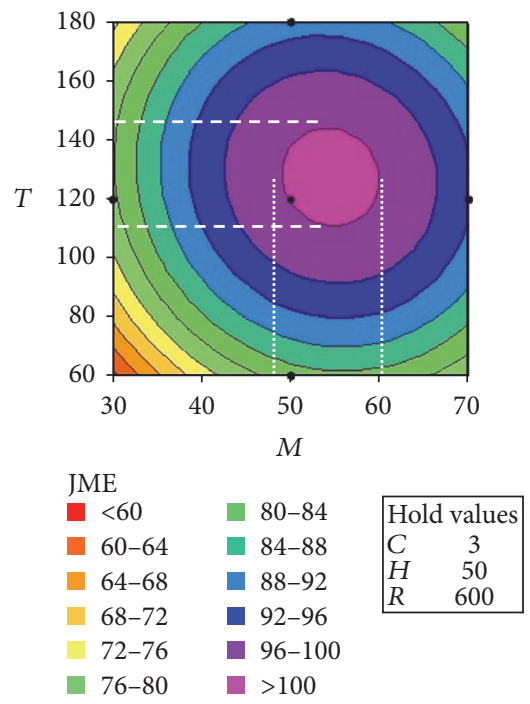

(e) Reaction time and methanol to oil ratio $(T \times M)$

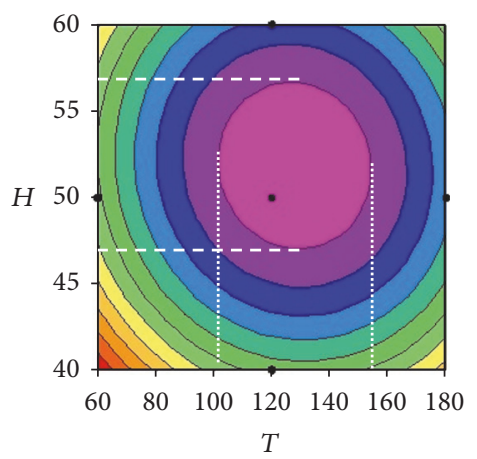

JME

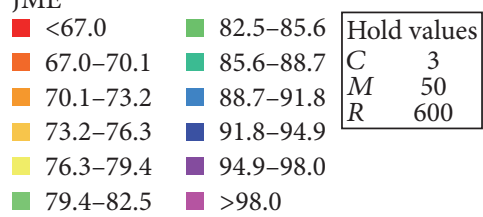

(h) Heating temperature and reaction time $(H \times T)$
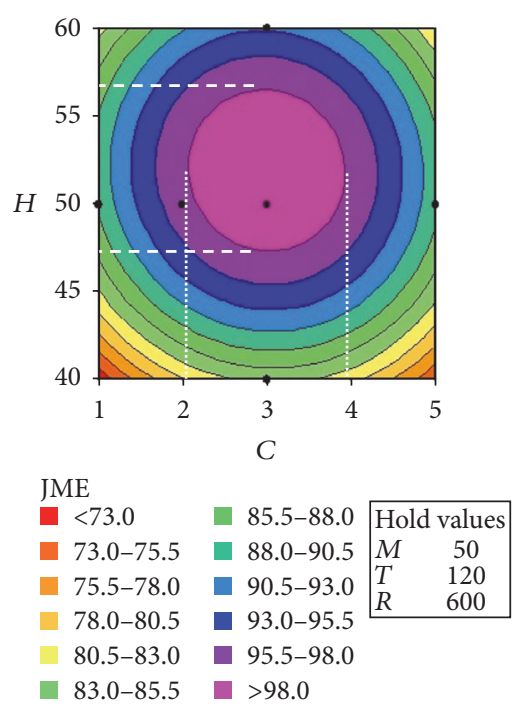

(c) Heating temperature and catalyst concentration $(H \times C)$

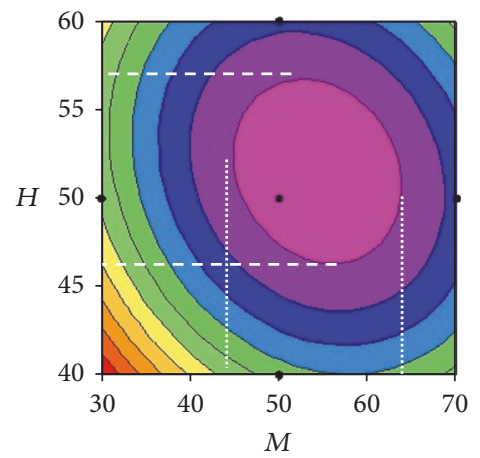

JME

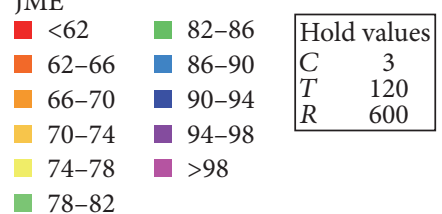

(f) Heating temperature and methanol to oil ratio $(H \times M)$

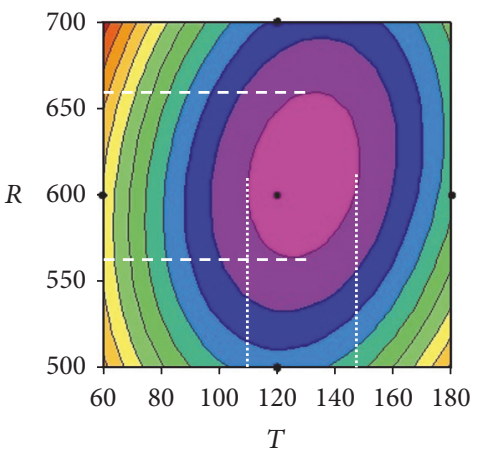

JME

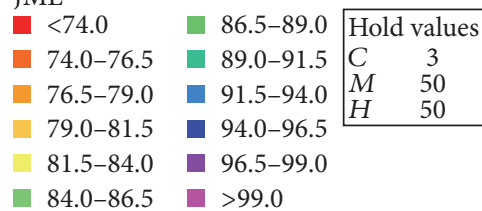

(i) Stirring speed and reaction time $(R \times T)$

Figure 8: Continued. 

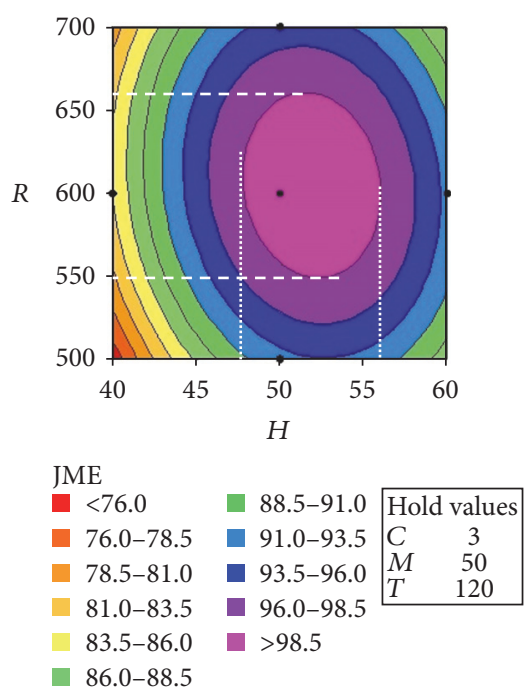

(j) Stirring speed and heating temperature $(R \times$

H)

FIGURE 8: Contour plots showing transesterification parametric interactions impact on JME yield.

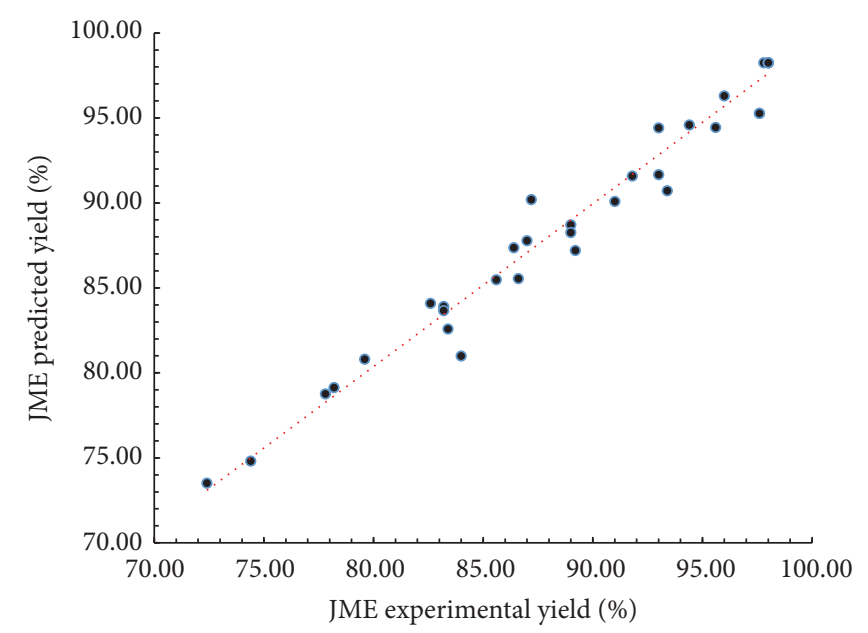

FIGURE 9: Comparative graph of JME predicted and experimental yields.

the interactions of heating temperature over $40^{\circ} \mathrm{C}-60^{\circ} \mathrm{C}$ with the catalyst loading, methanol molar ratio, reaction time, and stirring speed. The study of temperature effect is very crucial since a JME yield of " $\geq 98 \%$ " was reported on to $46^{\circ} \mathrm{C} \pm$ $1^{\circ} \mathrm{C}-56^{\circ} \mathrm{C} \pm 1^{\circ} \mathrm{C}$. Both higher and lower temperature ranges showed distinct negative impacts on the reaction process. The use of heterogeneous catalysts suffers from their poor rates of reaction compared to homogeneous catalysts; however, higher reaction pressures and temperatures can contribute in accelerating the reaction rate [75]. The reaction time gets shorter with higher temperatures and accelerates the rate of reaction but then rises the viscosity of reactants and reduces methyl esters conversion $[3,76]$. Also, the increase in reaction temperature eventually results in rapid evaporation of methanol which can greatly promotes saponification besides leading to side reactions and soap formation $[3,76]$. Despite a proper water cooling condenser attachment, if the operating temperature approaches close to boiling point of methanol, $64.7^{\circ} \mathrm{C}$, evaporation of methanol accelerates $[70,72]$. This effect was evident from the experimental results tabulated in Table 2. Likewise, the interaction $(M \times H)$ bears the relatively highest negative regression coefficient of " -4.479 " besides the fact that other interactions include $(C \times H),(T \times H)$, and $(H \times R)$. All these predominantly indicate that an increase in heating temperature does not appreciate the JME yield rather than reducing the whole reaction activity. Therefore, the heating temperature ranges are lower than methanol boiling point which minimizes its exponential vaporization and allows maintaining sufficient methanol levels during the transesterification.

3.4.5. Stirring Speed rpm (R). Stirring speed of reactants is one of the key reaction parameters in the biodiesel production through heterogeneous catalyzed transesterification process $[3,44,77]$. In Figures $8(\mathrm{~d}), 8(\mathrm{~g}), 8(\mathrm{i})$, and $8(\mathrm{j})$ the stirring speed interaction effects on JME yield together with the catalyst loading, methanol molar ratio, reaction time, and heating temperature were plotted. From the graphical results JME yield of " $\geq 99 \pm 0.5 \%$ " can be seen. Besides, the stirring speed interactions on the reaction time $(T \times R)$ and methanol to oil ratio $(M \times R)$ were comparably significant, with regression coefficients " +3.759 " and " +0.721 " as noted from (6). Even though the other two interactions $(C \times R)$ and $(H \times R)$ are indicated with negative regression coefficients, Figures $8(\mathrm{~d})$ and $8(\mathrm{j})$ contour plots demonstrate a JME yield of " $99.5 \%$ " and " $98.5 \%$," respectively. This emphasizes that a stirring speed is a productive reaction parameter in achieving a maximum JME yield.

3.5. Optimization of Reaction Parameters and Results Validation. Optimal \% JME yield was obtained by comprehensive integration analysis of linear and interaction impacts of all 
TABLE 5: Predicted JME yield \% data sets validation at optimal conditions with experimental results.

\begin{tabular}{lccccccc}
\hline Data set & \multicolumn{2}{c}{ Optimal condition } & \multicolumn{2}{c}{ JME yield (\%) } \\
& $\begin{array}{c}\text { Catalyst loading } \\
\text { (wt.\%) }\end{array}$ & $\begin{array}{c}\text { Methanol to oil } \\
\text { ratio (mol./mol.\%) }\end{array}$ & $\begin{array}{c}\text { Reaction time } \\
(\mathrm{min})\end{array}$ & $\begin{array}{c}\text { Heating } \\
\text { temperature } \\
\left({ }^{\circ} \mathrm{C}\right)\end{array}$ & $\begin{array}{c}\text { Stirring } \\
\text { speed (rpm) }\end{array}$ & Predicted & Experimental \\
\hline Set-1 & 2.95 & 54.30 & 157.44 & 50.43 & 621.92 & 98.02 & 97.04 \\
Set-2 & 3.07 & 54.29 & 157.30 & 50.43 & 624.79 & 98.14 & 97.26 \\
Set-3 & 3.10 & 54.72 & 157.66 & 50.37 & 622.11 & 98.03 & 97.05 \\
Set-4 & 3.29 & 54.31 & 156.41 & 50.45 & 627.48 & 98.25 & 97.37 \\
Set-5 & 3.22 & 53.23 & 138.78 & 51.98 & 561.18 & 98.89 & 98.00 \\
Set-6 & 3.09 & 55.28 & 106.53 & 50.92 & 631.88 & 98.42 & 97.53 \\
Set-7 & 3.15 & 54.65 & 157.58 & 50.38 & 622.81 & 98.05 & 97.85 \\
Set-8 & 3.29 & 53.42 & 137.73 & 51.97 & 560.38 & 98.80 & 97.92 \\
Set-9 & 3.10 & 54.24 & 127.87 & 51.31 & 611.11 & 99.20 & 98.80 \\
Set-10 & 2.96 & 55.96 & 128.71 & 51.31 & 611.11 & 99.41 & 98.62 \\
\hline
\end{tabular}

TABLE 6: Fatty acid composition analysis of JCO.

\begin{tabular}{lc}
\hline Fatty acid & JCO $(\%)$ \\
\hline Palmitic acid (C16:0) & 14.35 \\
Palmitoleic acid (C16:1) & 1.52 \\
Stearic acid (C18:0) & 7.02 \\
Oleic acid (C18:1) & 43.15 \\
Linoleic acid (C18:2) & 33.92 \\
Linolenic acid (C18:3) & 0.04 \\
\hline
\end{tabular}

five reaction parameters. The comparative analysis of both statistical and experimental results along with the interaction contour plots reveals a significant effect of a reaction parameter at a specific parameter levels. However, the minimum levels of any parameter were not intended to obtain optimal JME yield. The optimization of transesterification reaction parameters was carried out using a response surface optimizer tool and the results were validated for ten sets through confirmatory experiments successively. Data validation for ten sets together with the predicted and experimental results were tabulated as listed in Table 5. Among the ten validation test results $98.80 \%$ of JME yield was noted at optimal conditions C (3.10 wt.\%), $M$ (54.24 mol./mol.\%), T (127.87 min), $H$ $\left(51.31^{\circ} \mathrm{C}\right)$, and $R(612 \mathrm{rpm})$ for the data set-9. A similar result with a simple variation of " $-0.18 \%$ " JME yield was achieved for data set-10. The parametric optimal results are ascertained with previously published results [22-24, 49]. Further, the Razor shell $\mathrm{CaO}$ performance as a catalyst in converting the triglycerides of JCO to JME is comparable with literature reports by Tan et al. [14], Margaretha et al. [19], De Sousa et al. [21], Roschat et al. [50], McDevitt and Baun [51], Nasrazadani and Eureste [52], Zaki et al. [53], Mirghiasi et al. [54], Teo et al. [55], and Chen et al. [56].

3.6. Analysis of Razor Shell CaO Reusability, Leaching Analysis, and Transesterification with Reference Catalyst. The Razor shell $\mathrm{CaO}$ catalyst reusability transesterification experiments of the pretreated JCO and methanol were carried out with optimal conditions of C (3.10 wt.\%), $M(54.24 \mathrm{~mol} . / \mathrm{mol} . \%)$, $T$ (127.87 $\mathrm{min}), H\left(51.31^{\circ} \mathrm{C}\right)$, and $R(612 \mathrm{rpm})$ as obtained and under similar experimental protocols for five successive catalyst reuse cycles. Figure 10(a) shows variations in JME yield from five successive reuse cycles 97.62\%, 95.75\%, 91.52\%, $84.33 \%$, and $76.40 \%$, respectively. The SEM monograms (Figures 10(b)-10(f)) depict changes in surface morphology of reused Razor shell $\mathrm{CaO}$ catalyst over five cycles successively. The reduction in JME yield may be due to the gradual loss of active sites on the catalyst surface, particle agglomerations with other reactant molecules, and/or calcium catalyst leaching to the biodiesel $[13,14]$. An averaNge JME yield of $93.6 \%$ was noted up to the 4 th catalyst reuse cycle. However, during the 5th catalyst reuse cycle JME yield was $76.40 \%$, which is remarkably less by $7.93 \%$ from the 4 th reuse cycle. Besides, the leaching of Razor shell $\mathrm{CaO}$ catalyst was carried out successively using AAS for measuring calcium ion $\left(\mathrm{Ca}^{2+}\right)$ leached to JME. The test results indicate $\mathrm{Ca}^{2+}$ dispersion range of $1.43 \mathrm{ppm} \pm 0.11$ to $4.25 \mathrm{ppm} \pm 0.21$ during the 1 st and 4th reuse cycles, which indicate compliance with EN14214 fuel standards. However, from the 5th reuse cycle, $\mathrm{Ca}^{2+}$ of $6.67 \mathrm{ppm} \pm 1.09$ was reported and subsequently dropped in JME yield besides increased leaching. Hence, it can be concluded that the Razor shell $\mathrm{CaO}$ is stable for four reuse cycles. Transesterification of JCO using lab grade $\mathrm{CaO}$ together with catalyst reuse tests was conducted at optimal conditions as obtained. Results of \% JME yield using from both Razor shell $\mathrm{CaO}$ and lab grade $\mathrm{CaO}$ are shown in Figure 10. The JME yield achieved from Razor shell $\mathrm{CaO}$ is higher besides good catalytic performance over its reusability. Moreover, the JME yield obtained from present investigations is comparably higher than other researchers, Tan et al. [14], reported. This variation in JME yield can be attributed to the higher catalyst surface area, particle size, and pore volume of Razor shell $\mathrm{CaO}$ compared to catalysts used by Tan et al. [14].

3.7. JME Fuel Properties Analysis. The JME fuel property test results such as density at $15^{\circ} \mathrm{C}$, calorific value, flash point, cetane value, specific gravity at $15^{\circ} \mathrm{C}$, viscosity at $40^{\circ} \mathrm{C}$, water content, ash content, acid value, monoglyceride, 


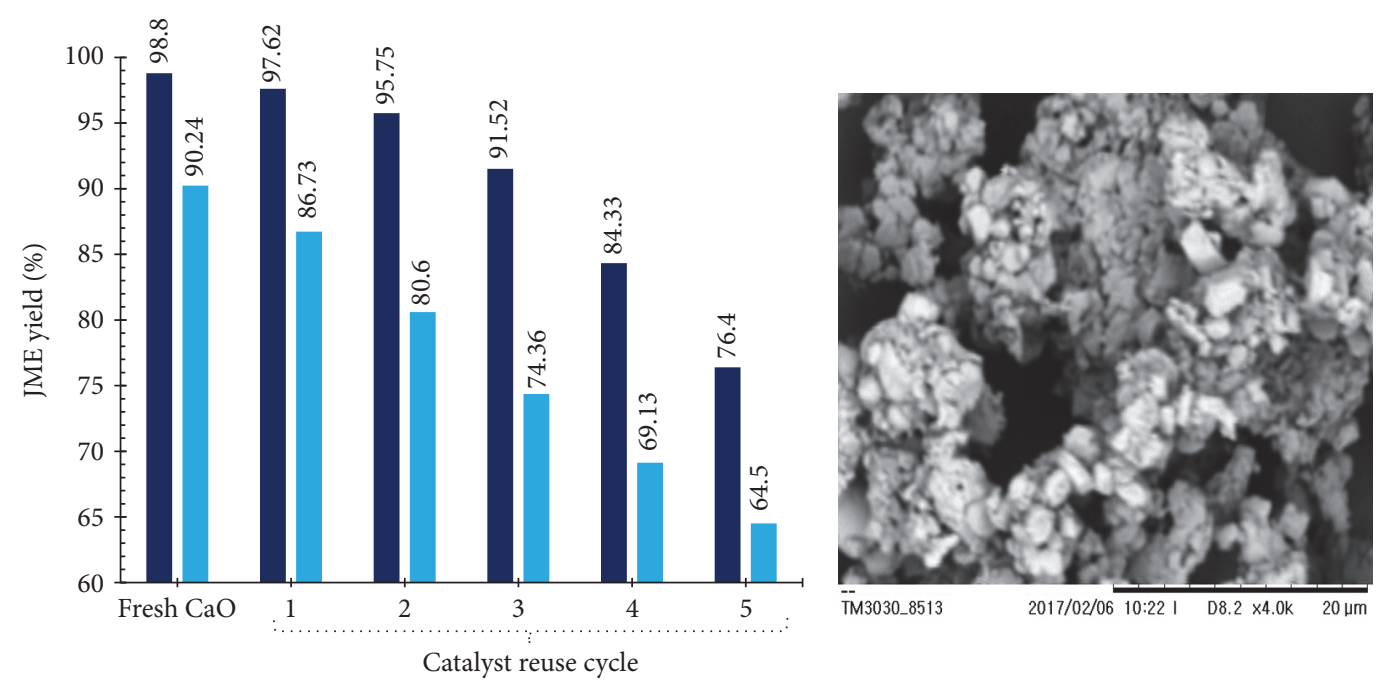

- Razor shell $\mathrm{CaO}$ catalyst

- Lab grade $\mathrm{CaO}$

(a)

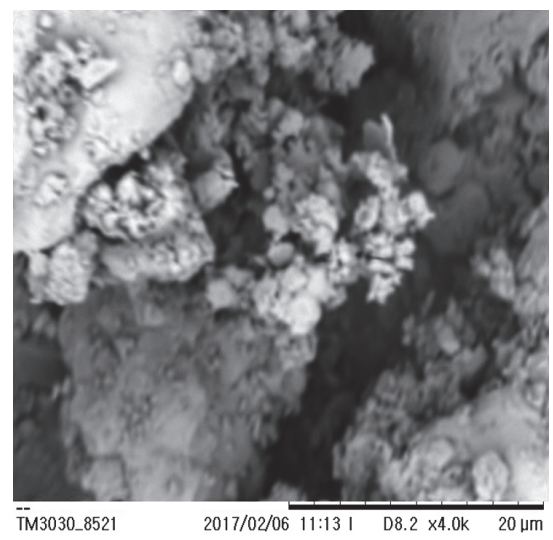

(c)

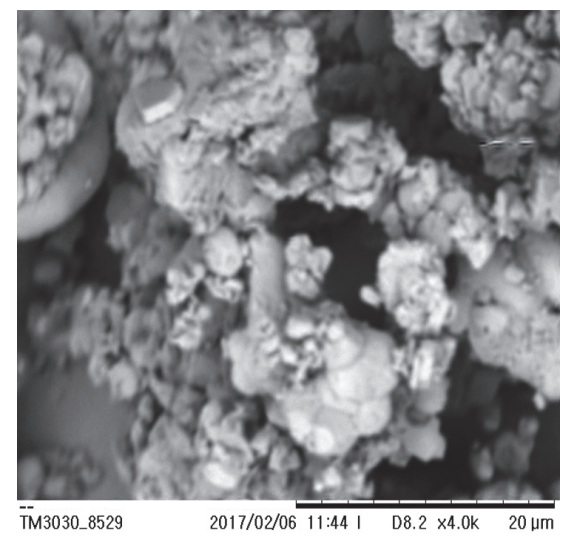

(d)

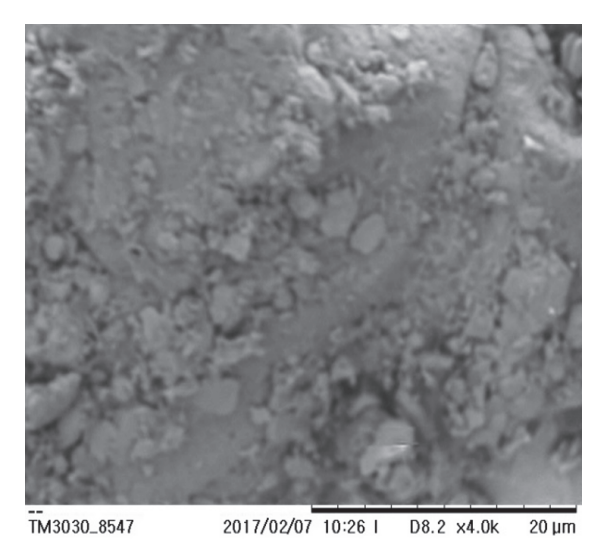

(f) (b)

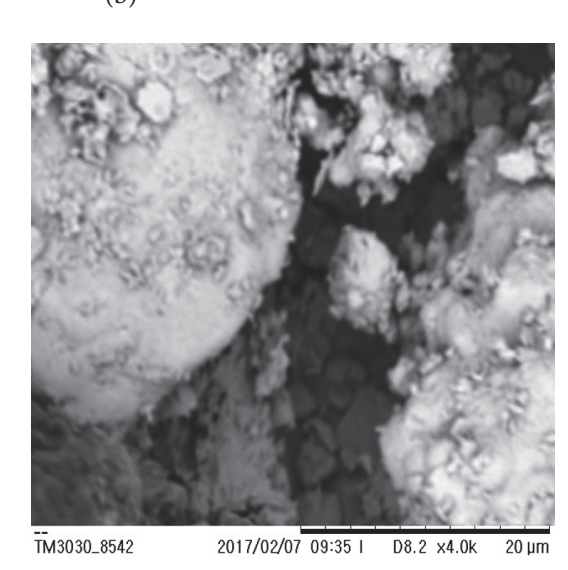

(e) 
TABLE 7: JME fuel properties.

\begin{tabular}{|c|c|c|}
\hline Fuel property (units) & JME & EN 14214 limit \\
\hline Density at $15^{\circ} \mathrm{C}\left(\mathrm{kg} / \mathrm{m}^{3}\right)$ & 883 & $860-900$ \\
\hline Calorific value (MJ/kg) & 36.284 & - \\
\hline Flash point $\left({ }^{\circ} \mathrm{C}\right)$ & 167 & $>101$ \\
\hline Cetane value & 52 & $>47$ \\
\hline Specific gravity at $15^{\circ} \mathrm{C}(\mathrm{g} / \mathrm{ml})$ & 0.878 & $0.86-0.90$ \\
\hline viscosity at $40^{\circ} \mathrm{C}\left(\mathrm{mm}^{2} / \mathrm{s}\right)$ & 4.22 & $3.5-5.0$ \\
\hline Water content $(\mathrm{Wt} \%)$ & 0.044 & $<0.05$ \\
\hline Ash content (g/100 g) & $<0.01$ & $<0.01$ \\
\hline Acid value (Mg KOH/g) & 0.28 & $<0.5$ \\
\hline Monoglyceride (Wt\%) & 0.311 & $<0.80$ \\
\hline Diglyceride (Wt\%) & 0.033 & $<0.20$ \\
\hline Triglyceride (Wt\%) & 0 & $<0.20$ \\
\hline Free glycerin $(\mathrm{Wt} \%)$ & 0 & $<0.02$ \\
\hline Total ester $(\mathrm{Wt} \%)$ & 99.11 & $>96.5$ \\
\hline Total glycerin $(\mathrm{Wt} \%)$ & 0.03 & $<0.25$ \\
\hline
\end{tabular}

diglyceride, triglyceride, free glycerine, total ester content, and total glycerine contents are summarized in Table 7. The results are compliance with the European biodiesel standard EN14214; thus JME indicates its suitability as a green biodiesel source.

\section{Conclusions}

Synthesis of heterogeneous $\mathrm{CaO}$ catalyst using Razor shells conformed by spectral characterization results of FTIR, SEM, XRD, BET\&BJH, and PSA with a crystalline size of $87.2 \mathrm{~nm}, S_{\mathrm{BET}}$ of $92.63 \mathrm{~m}^{2} / \mathrm{g}$, pore diameters of $37.311 \mathrm{~nm}$, and pore volume of $0.613 \mathrm{cc} / \mathrm{g}$ which signifies $\mathrm{CaO}$ as an active catalyst. $\mathrm{CaO}$ was derived using a green synthesis protocol "calcination-hydro aeration-dehydration." The catalyst yielded an optimal Jatropha methyl ester (JME) of $98.80 \%$ via two-step transesterification of Jatropha curcas oil (JCO) at $C$ (3.10 wt.\%), $M$ (54.24 mol./mol.\%), $T$ (127.87 min), $H$ $\left(51.31^{\circ} \mathrm{C}\right)$, and $R(612 \mathrm{rpm})$. The reaction kinetics and JME yield optimization were investigated utilizing a five-factorfive-level, two-block, half factorial, central composite design (CCD) based response surface method (RSM) design. The atomic absorption spectroscopic characterization of JME showed minimal leaching of calcium to JME until catalyst of 4 th reuse cycle. The amount of Ca leaching increases for each type of reuse and subsequently reduces JME yield. The fuel properties tested according to biodiesel standards EN 14214 comply with JME's suitability as a green biodiesel and offers sustainable benefits.

\section{Conflicts of Interest}

The authors declare that there are no conflicts of interest regarding the publishing of this paper.

\section{Acknowledgments}

The authors would like to thank Faculty of Engineering, UNIMAS, and all the staff members for providing research facilities and continuous support during this work. The first author, A. N. R. Reddy, would greatly acknowledge and express his highest gratitude to Ministry of Higher Education, Malaysia, for awarding prestigious Malaysian International Scholarship (MIS) 2015; KPT.B.600-4/1/12 (60).

\section{References}

[1] G. B. Asheim, WPS1302, The World Bank, Washington, DC, USA, 1994, http://www-wds.worldbank.org/servlet/WDSContentServer/WDSP/IB/1994/05/01/000009265_3970716141011/ Rendered/PDF/multi0page.pdf.

[2] US-EPA, "RFS2: EPA-420-R-10-003, Washington DC, USA," 2010 http://www3.epa.gov/otaq/renewablefuels/420r10003.pdf.

[3] J. Qian, H. Shi, and Z. Yun, "Preparation of biodiesel from Jatropha curcas L. oil produced by two-phase solvent extraction," Bioresource Technology, vol. 101, no. 18, pp. 7025-7031, 2010.

[4] L. C. Meher, C. P. Churamani, M. Arif, Z. Ahmed, and S. N. Naik, "Jatropha curcas as a renewable source for bio-fuels-a review," Renewable and Sustainable Energy Reviews, vol. 26, pp. 397-407, 2013.

[5] I. Noshadi, N. A. S. Amin, and R. S. Parnas, "Continuous production of biodiesel from waste cooking oil in a reactive distillation column catalyzed by solid heteropolyacid: optimization using response surface methodology (RSM)," Fuel, vol. 94, pp. 156-164, 2012.

[6] E. F. Aransiola, T. V. Ojumu, O. O. Oyekola, T. F. Madzimbamuto, and D. I. O. Ikhu-Omoregbe, "A review of current technology for biodiesel production: state of the art," Biomass and Bioenergy, vol. 61, pp. 276-297, 2014.

[7] J. M. Marchetti, V. U. Miguel, and A. F. Errazu, "Possible methods for biodiesel production," Renewable and Sustainable Energy Reviews, vol. 11, no. 6, pp. 1300-1311, 2007.

[8] S. H. Teo, Y. H. Taufiq-Yap, U. Rashid, and A. Islam, "Hydrothermal effect on synthesis, characterization and catalytic properties of calcium methoxide for biodiesel production from crude Jatropha curcas," RSC Advances, vol. 5, no. 6, pp. 4266-4276, 2015. 
[9] E. W. Thiele, "Relation between catalytic activity and size of particle," Industrial \& Engineering Chemistry, vol. 31, no. 7, pp. 916-920, 1939.

[10] A. Buasri, N. Chaiyut, V. Loryuenyong, P. Worawanitchaphong, and S. Trongyong, "Calcium oxide derived from waste shells of mussel, cockle, and scallop as the heterogeneous catalyst for biodiesel production," The Scientific World Journal, vol. 2013, Article ID 460923, 7 pages, 2013.

[11] H. A. Choudhury, P. P. Goswami, R. S. Malani, and V. S. Moholkar, "Ultrasonic biodiesel synthesis from crude Jatropha curcas oil with heterogeneous base catalyst: mechanistic insight and statistical optimization," Ultrasonics Sonochemistry, vol. 21, no. 3, pp. 1050-1064, 2014.

[12] S. H. Teo, U. Rashid, and Y. H. Taufiq-Yap, "Biodiesel production from crude Jatropha Curcas oil using calcium based mixed oxide catalysts," Fuel, vol. 136, pp. 244-252, 2014.

[13] Y. H. Taufiq-Yap, H. V. Lee, M. Z. Hussein, and R. Yunus, "Calcium-based mixed oxide catalysts for methanolysis of Jatropha curcas oil to biodiesel," Biomass and Bioenergy, vol. 35, no. 2, pp. 827-834, 2011.

[14] Y. H. Tan, M. O. Abdullah, C. Nolasco-Hipolito, and Y. H. Taufiq-Yap, "Waste ostrich- and chicken-eggshells as heterogeneous base catalyst for biodiesel production from used cooking oil: catalyst characterization and biodiesel yield performance," Applied Energy, vol. 160, pp. 58-70, 2015.

[15] A. Kawashima, K. Matsubara, and K. Honda, "Acceleration of catalytic activity of calcium oxide for biodiesel production," Bioresource Technology, vol. 100, no. 2, pp. 696-700, 2009.

[16] R. Shan, C. Zhao, P. Lv, H. Yuan, and J. Yao, "Catalytic applications of calcium rich waste materials for biodiesel: current state and perspectives," Energy Conversion and Management, vol. 127, pp. 273-283, 2016.

[17] M. Mohamed, N. A. Rashidi, S. Yusup, L. K. Teong, U. Rashid, and R. M. Ali, "Effects of experimental variables on conversion of cockle shell to calcium oxide using thermal gravimetric analysis," Journal of Cleaner Production, vol. 37, pp. 394-397, 2012.

[18] S. Nurdin, "Activated Paphia undulate shells waste (APSW): a cost-effective catalyst for biodiesel synthesis from Rubber and Jatropha curcas seeds oil (RSOME \& JSOME)," International Journal of Chemical Engineering and Applications, vol. 5, no. 6, pp. 483-488, 2014.

[19] Y. Y. Margaretha, H. S. Prastyo, A. Ayucitra, and S. Ismadji, "Calcium oxide from pomacea sp. shell as a catalyst for biodiesel production," International Journal of Energy and Environmental Engineering, vol. 3, no. 1, article 33, 2012.

[20] K. N. Islam, M. Z. B. A. Bakar, M. E. Ali et al., "A novel method for the synthesis of calcium carbonate (aragonite) nanoparticles from cockle shells," Powder Technology, vol. 235, pp. 70-75, 2013.

[21] F. P. De Sousa, G. P. Dos Reis, C. C. Cardoso, W. N. Mussel, and V. M. D. Pasa, "Performance of $\mathrm{CaO}$ from different sources as a catalyst precursor in soybean oil transesterification: kinetics and leaching evaluation," Journal of Environmental Chemical Engineering, vol. 4, no. 2, pp. 1970-1977, 2016.

[22] A. Okullo, A. K. Temu, J. W. Ntalikwa, and P. Ogwok, "Optimization of biodiesel production from Jatropha oil," International Journal of Engineering Research in Africa, vol. 3, pp. 62-73, 2010.

[23] P. Goyal, M. P. Sharma, and S. Jain, "Optimization of esterification and transesterification of high FFA Jatropha curcas oil using response surface methodology," Journal of Petroleum Science and Engineering, vol. 1, no. 3, pp. 36-43, 2012.
[24] U. Rashid, F. Anwar, B. R. Moser, and S. Ashraf, "Production of sunflower oil methyl esters by optimized alkali-catalyzed methanolysis," Biomass and Bioenergy, vol. 32, no. 12, pp. 1202$1205,2008$.

[25] R. Anr, A. A. Saleh, M. S. Islam, S. Hamdan, and M. A. Maleque, "Biodiesel production from crude Jatropha oil using a highly active heterogeneous nanocatalyst by optimizing transesterification reaction parameters," Energy and Fuels, vol. 30, no. 1, pp. 334-343, 2016.

[26] S. Pradhan, C. S. Madankar, P. Mohanty, and S. N. Naik, "Optimization of reactive extraction of castor seed to produce biodiesel using response surface methodology," Fuel, vol. 97, pp. 848-855, 2012.

[27] A. Kumar Tiwari, A. Kumar, and H. Raheman, "Biodiesel production from jatropha oil (Jatropha curcas) with high free fatty acids: an optimized process," Biomass and Bioenergy, vol. 31, no. 8, pp. 569-575, 2007.

[28] G. Vicente, A. Coteron, M. Martinez, and J. Aracil, "Application of the factorial design of experiments and response surface methodology to optimize biodiesel production," Industrial Crops and Products, vol. 8, no. 1, pp. 29-35, 1998.

[29] S. Dhingra, K. K. Dubey, and G. Bhushan, "Enhancement in Jatropha-based biodiesel yield by process optimisation using design of experiment approach," International Journal of Sustainable Energy, vol. 33, no. 4, pp. 842-853, 2014.

[30] S. Dhingra, G. Bhushan, and K. K. Dubey, "Development of a combined approach for improvement and optimization of karanja biodiesel using response surface methodology and genetic algorithm," Frontiers in Energy, vol. 7, no. 4, pp. 495-505, 2013.

[31] D. Kanakaraju, C. Jios, and S. M. Long, "Heavy metal concentrations in the Razor Clams (Solen spp) from Muara Tebas, Sarawak," Malaysian Journal of Analytical Sciences, vol. 12, pp. 53-58, 2008.

[32] S. Akmar and K. Ab. Rahim, "Razor Clam (Solen spp.) fishery in Sarawak, Malaysia," Kuroshio Science, vol. 5, no. 1, pp. 87-94, 2011.

[33] M. F. Hossen, S. Hamdan, and M. R. Rahman, "Review on the risk assessment of heavy metals in Malaysian clams," The Scientific World Journal, vol. 2015, Article ID 905497, 7 pages, 2015.

[34] K. N. Islam, M. Z. B. A. Bakar, M. M. Noordin, M. Z. Bin Hussein, N. S. B. A. Rahman, and M. E. Ali, "Characterisation of calcium carbonate and its polymorphs from cockle shells (Anadara granosa)," Powder Technology, vol. 213, no. 1, pp. 188191, 2011.

[35] A. N. R. Reddy, A. A. Saleh, S. Islam, and S. Hamdan, "Optimization of transesterification parameters for optimal biodiesel yield from Crude Jatropha oil using a newly synthesized seashell catalyst," Journal of Engineering Science and Technology, In press.

[36] A. N. R. Reddy, A. Saleh, M. S. Islam, and S. Hamdan, "Active heterogeneous $\mathrm{CaO}$ catalyst synthesis from Anadara granosa (Kerang) seashells for Jatropha biodiesel production," MATEC Web of Conferences, vol. 87, Article ID 02008, 6 pages, 2017.

[37] S. Ismail, A. S. Ahmed, R. Anr, and S. Hamdan, "Biodiesel production from castor oil by using calcium oxide derived from mud clam shell," Journal of Renewable Energy, vol. 2016, Article ID 5274917, 8 pages, 2016.

[38] A. N. R. Reddy, A. A. Saleh, M. D. S. Islam, and S. Hamdan, "Methanolysis of Crude Jatropha oil using heterogeneous catalyst from the seashells and eggshells as green biodiesel," ASEAN 
Journal on Science and Technology for Development, vol. 32, no. 1, pp. 16-30, 2015.

[39] X. Deng, Z. Fang, and Y. H. Liu, "Ultrasonic transesterification of Jatropha curcas L. oil to biodiesel by a two-step process," Energy Conversion and Management, vol. 51, no. 12, pp. 28022807, 2010.

[40] S. Niju, K. M. Meera Sheriffa Begum, and N. Anantharaman, "Enhancement of biodiesel synthesis over highly active $\mathrm{CaO}$ derived from natural white bivalve clam shell," Arabian Journal of Chemistry, vol. 9, pp. 633-639, 2016.

[41] S. Niju, M. S. Begum, and N. Anantharaman, "Modification of egg shell and its application in biodiesel production," Journal of Saudi Chemical Society, vol. 18, no. 5, pp. 702-706, 2014.

[42] B. Yoosuk, P. Udomsap, B. Puttasawat, and P. Krasae, "Improving transesterification acitvity of $\mathrm{CaO}$ with hydration technique," Bioresource Technology, vol. 101, no. 10, pp. 3784-3786, 2010.

[43] A. Bazargan, M. D. Kostić, O. S. Stamenković, V. B. Veljković, and G. McKay, "A calcium oxide-based catalyst derived from palm kernel shell gasification residues for biodiesel production," Fuel, vol. 150, pp. 519-525, 2015.

[44] P.-L. Boey, G. P. Maniam, and S. A. Hamid, "Biodiesel production via transesterification of palm olein using waste mud crab (Scylla serrata) shell as a heterogeneous catalyst," Bioresource Technology, vol. 100, no. 24, pp. 6362-6368, 2009.

[45] A. K. Endalew, Y. Kiros, and R. Zanzi, "Heterogeneous catalysis for biodiesel production from Jatropha curcas oil (JCO)," Energy, vol. 36, no. 5, pp. 2693-2700, 2011.

[46] H. V. Lee, J. C. Juan, N. F. Binti Abdullah, R. Nizah MF, and Y. H. Taufiq-Yap, "Heterogeneous base catalysts for edible palm and non-edible Jatropha-based biodiesel production," Chemistry Central Journal, vol. 8, no. 1, article 30, 2014.

[47] X. Deng, Z. Fang, Y.-H. Liu, and C.-L. Yu, "Production of biodiesel from Jatropha oil catalyzed by nanosized solid basic catalyst," Energy, vol. 36, no. 2, pp. 777-784, 2011.

[48] H. J. Berchmans and S. Hirata, "Biodiesel production from crude Jatropha curcas L. seed oil with a high content of free fatty acids," Bioresource Technology, vol. 99, no. 6, pp. 1716-1721, 2008.

[49] D. Vujicic, D. Comic, A. Zarubica, R. Micic, and G. Boskovic, "Kinetics of biodiesel synthesis from sunflower oil over $\mathrm{CaO}$ heterogeneous catalyst," Fuel, vol. 89, no. 8, pp. 2054-2061, 2010.

[50] W. Roschat, T. Siritanon, T. Kaewpuang, B. Yoosuk, and V. Promarak, "Economical and green biodiesel production process using river snail shells-derived heterogeneous catalyst and cosolvent method," Bioresource Technology, vol. 209, pp. 343-350, 2016.

[51] N. T. McDevitt and W. L. Baun, "Infrared absorption study of metal oxides in the low frequency region (700-240 cm-1)," Spectrochimica Acta, vol. 20, no. 5, pp. 799-808, 1964.

[52] S. Nasrazadani and E. Eureste, "Application of FTIR for Quantitative Lime Analysis," Denton Texas, 2008 https://www.ntis .gov/.

[53] M. I. Zaki, H. Knözinger, B. Tesche, and G. A. H. Mekhemer, "Influence of phosphonation and phosphation on surface acidbase and morphological properties of $\mathrm{CaO}$ as investigated by in situ FTIR spectroscopy and electron microscopy," Journal of Colloid and Interface Science, vol. 303, no. 1, pp. 9-17, 2006.

[54] Z. Mirghiasi, F. Bakhtiari, E. Darezereshki, and E. Esmaeilzadeh, "Preparation and characterization of $\mathrm{CaO}$ nanoparticles from $\mathrm{Ca}(\mathrm{OH}) 2$ by direct thermal decomposition method," Journal of Industrial and Engineering Chemistry, vol. 20, no. 1, pp. 113-117, 2014.
[55] S. H. Teo, A. Islam, F. L. Ng, and Y. H. Taufiq-Yap, "Biodiesel synthesis from photoautotrophic cultivated oleoginous microalgae using a sand dollar catalyst," RSC Advances, vol. 5, no. 58, pp. 47140-47152, 2015.

[56] G. Chen, R. Shan, J. Shi, and B. Yan, "Ultrasonic-assisted production of biodiesel from transesterification of palm oil over ostrich eggshell-derived $\mathrm{CaO}$ catalysts," Bioresource Technology, vol. 171, pp. 428-432, 2014.

[57] Y. Ren, Z. Ma, and P. G. Bruce, "Ordered mesoporous metal oxides: synthesis and applications," Chemical Society Reviews, vol. 41, no. 14, p. 4909, 2012.

[58] Ž. Kesić, I. Lukić, D. Brkić et al., "Mechanochemical preparation and characterization of $\mathrm{CaO} \cdot \mathrm{ZnO}$ used as catalyst for biodiesel synthesis," Applied Catalysis A: General, vol. 427-428, pp. 58-65, 2012.

[59] E. W. Thiele, "Relation between catalytic activity and size of particle," Industrial \& Engineering Chemistry, vol. 31, no. 7, pp. 916-920, 1939.

[60] D. C. Montgomery, Design and Analysis of Experiments, John Wiley \& Sons, 8th edition, 2012, https://books.google.com.my/ books?id=XQAcAAAAQBAJ.

[61] H. Ceylan, S. Kubilay, N. Aktas, and N. Sahiner, "An approach for prediction of optimum reaction conditions for laccasecatalyzed bio-transformation of 1-naphthol by response surface methodology (RSM)," Bioresource Technology, vol. 99, no. 6, pp. 2025-2031, 2008.

[62] P. Verma, M. P. Sharma, and G. Dwivedi, "Impact of alcohol on biodiesel production and properties," Renewable and Sustainable Energy Reviews, vol. 56, pp. 319-333, 2016.

[63] G. Joshi, D. S. Rawat, B. Y. Lamba et al., "Transesterification of Jatropha and Karanja oils by using waste egg shell derived calcium based mixed metal oxides," Energy Conversion and Management, vol. 96, pp. 258-267, 2015.

[64] A. P. S. Chouhan and A. K. Sarma, "Modern heterogeneous catalysts for biodiesel production: a comprehensive review," Renewable and Sustainable Energy Reviews, vol. 15, no. 9, pp. 4378-4399, 2011.

[65] M. Sánchez, F. Bergamin, E. Peña, M. Martínez, and J. Aracil, "A comparative study of the production of esters from Jatropha oil using different short-chain alcohols: optimization and characterization," Fuel, vol. 143, pp. 183-188, 2015.

[66] G. Knothe, "Analyzing biodiesel: standards and other methods," Journal of the American Oil Chemists' Society, vol. 83, no. 10, pp. 823-833, 2006.

[67] K. Boonmee, S. Chuntranuluck, V. Punsuvon, and P. Silayoi, "Optimization of biodiesel production from Jatropha oil (Jatropha curcas L.) using response surface methodology," Journal of Sustainable Energy \& Environment, vol. 299, pp. 290-299, 2010.

[68] R. Sathish Kumar, K. Sureshkumar, and R. Velraj, "Optimization of biodiesel production from Manilkara zapota (L.) seed oil using Taguchi method," Fuel, vol. 140, pp. 90-96, 2015.

[69] F. Ma and M. A. Hanna, "Biodiesel production: a review," Bioresource Technology, vol. 70, no. 1, pp. 1-15, 1999.

[70] D. Y. C. Leung, X. Wu, and M. K. H. Leung, "A review on biodiesel production using catalyzed transesterification," Applied Energy, vol. 87, no. 4, pp. 1083-1095, 2010.

[71] D. Y. C. Leung and Y. Guo, "Transesterification of neat and used frying oil: optimization for biodiesel production," Fuel Processing Technology, vol. 87, no. 10, pp. 883-890, 2006.

[72] B. Freedman, E. H. Pryde, and T. L. Mounts, "Variables affecting the yields of fatty esters from transesterified vegetable oils," 
Journal of the American Oil Chemists Society, vol. 61, no. 10, pp. 1638-1643, 1984.

[73] K. Prasertsit, P. Phoosakul, and S. Sukmanee, "Use of calcium oxide in palm oil methyl ester production," Songklanakarin Journal of Science and Technology, vol. 36, no. 2, pp. 195-200, 2014.

[74] M. Kouzu, T. Kasuno, M. Tajika, S. Yamanaka, and J. Hidaka, "Active phase of calcium oxide used as solid base catalyst for transesterification of soybean oil with refluxing methanol," Applied Catalysis A: General, vol. 334, no. 1-2, pp. 357-365, 2008.

[75] A. C. Alba-Rubio, M. L. Alonso Castillo, M. C. G. Albuquerque, R. Mariscal, C. L. Cavalcante Jr., and M. L. Granados, "A new and efficient procedure for removing calcium soaps in biodiesel obtained using $\mathrm{CaO}$ as a heterogeneous catalyst," Fuel, vol. 95, pp. 464-470, 2012.

[76] S. M. Hailegiorgis, S. Mahadzir, and D. Subbarao, "Parametric study and optimization of in situ transesterification of Jatropha curcas $\mathrm{L}$ assisted by benzyltrimethylammonium hydroxide as a phase transfer catalyst via response surface methodology," Biomass and Bioenergy, vol. 49, pp. 63-73, 2013.

[77] P. K. Roy, S. Datta, S. Nandi, and F. Al Basir, "Effect of mass transfer kinetics for maximum production of biodiesel from Jatropha Curcas oil: a mathematical approach," Fuel, vol. 134, pp. 39-44, 2014. 

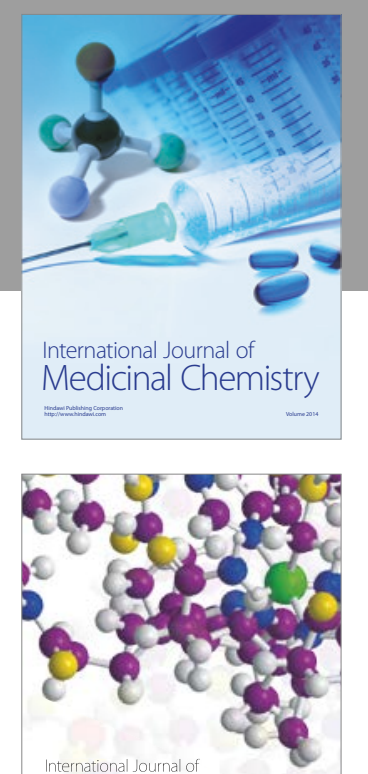

Carbohydrate Chemistry

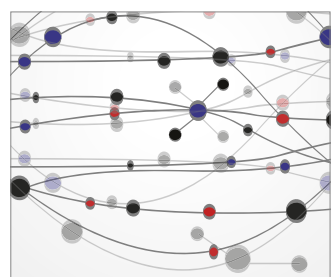

The Scientific World Journal
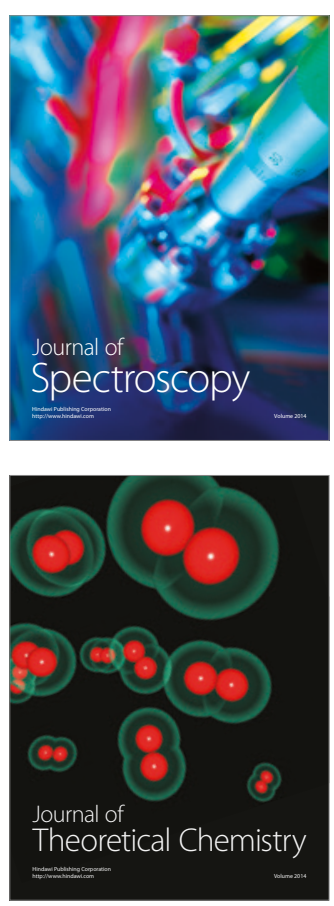
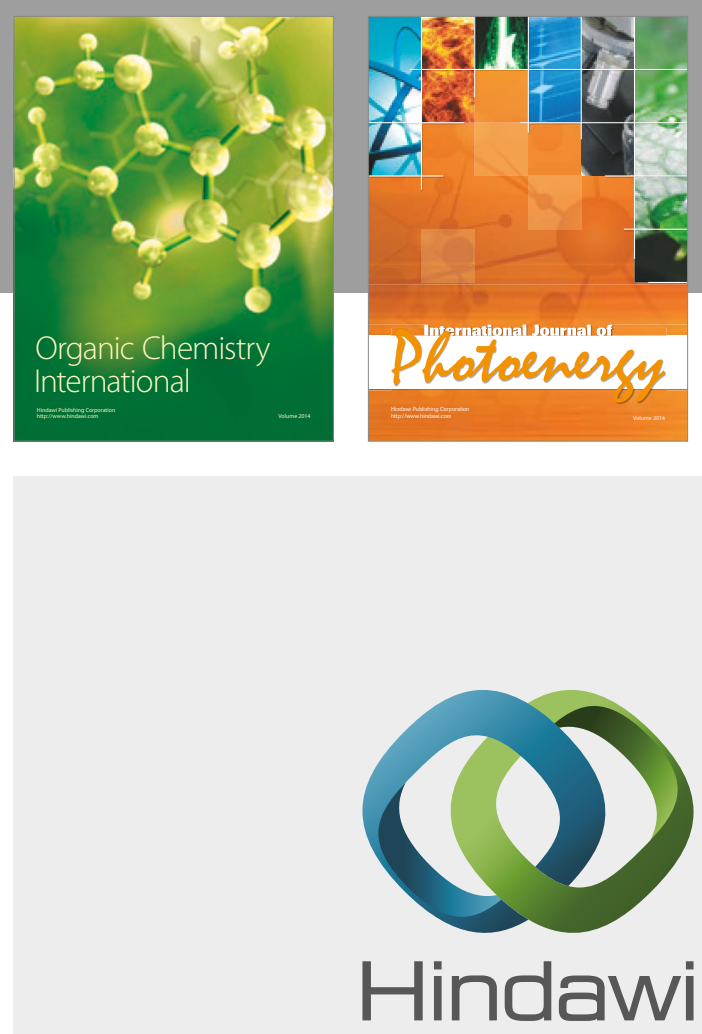

Submit your manuscripts at

https://www.hindawi.com

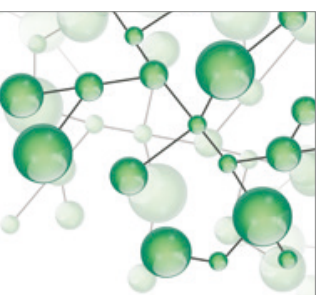

International Journal of

Inorganic Chemistry

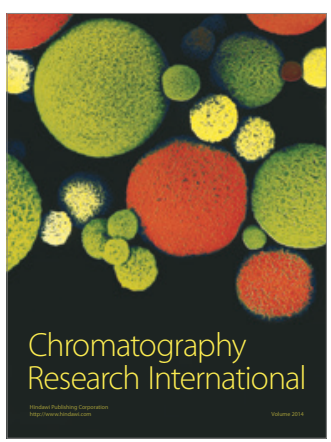

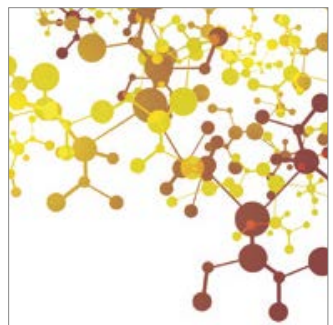

Applied Chemistry
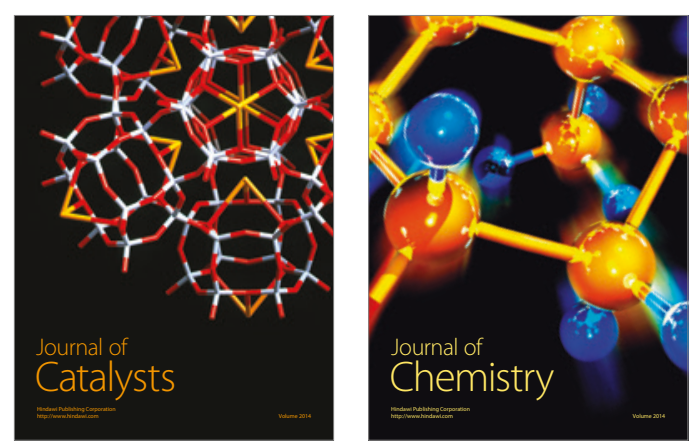
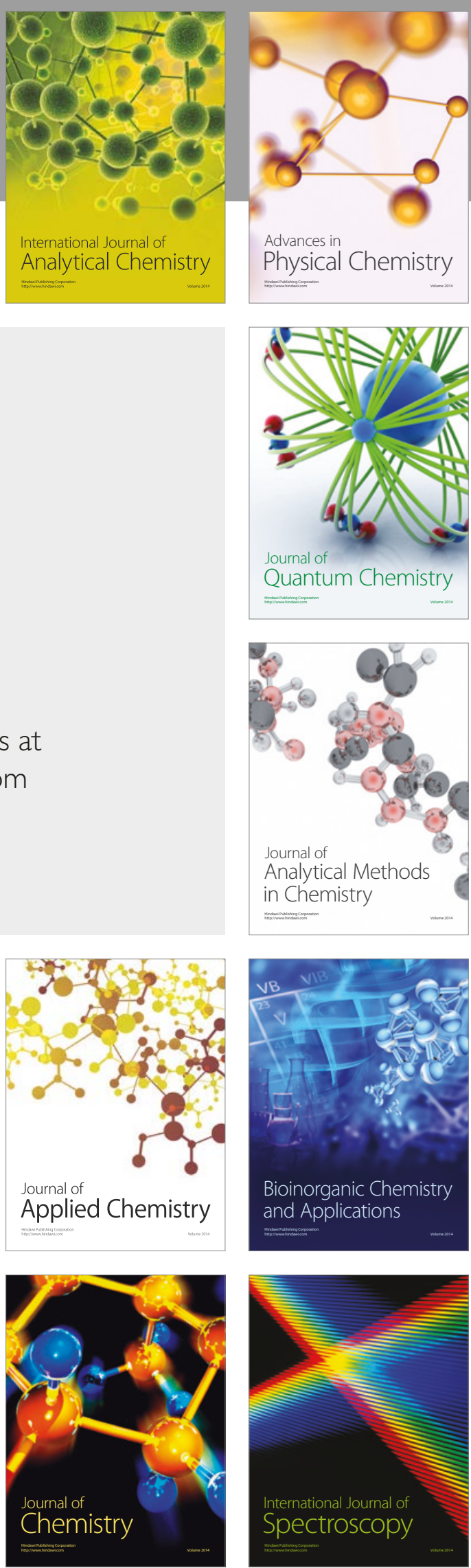